\title{
Mapping cropping intensity of smallholder farms: A comparison of methods using multiple sensors
}

\author{
Meha Jain ${ }^{\text {a,* }}$, Pinki Mondal ${ }^{\text {a }}$, Ruth S. DeFries ${ }^{\text {a }}$, Christopher Small ${ }^{\text {b }}$, Gillian L. Galford ${ }^{\text {a,c }}$ \\ a Department of Ecology, Evolution and Environmental Biology, Columbia University, New York, NY 10027, USA \\ b Lamont Doherty Earth Observatory, Columbia University, Palisades, NY 10964, USA \\ c Gund Institute for Ecological Economics, Rubenstein School of Environment and Natural Resources, University of Vermont, VT 05405, USA
}

\section{A R T I C L E I N F O}

\section{Article history:}

Received 23 July 2012

Received in revised form 20 February 2013

Accepted 23 February 2013

Available online 9 April 2013

\section{Keywords:}

Smallholder agriculture

MODIS

Landsat

Cropping intensity

Temporal mixture model

Hierarchical training

South Asia

\begin{abstract}
A B S T R A C T
The food security of smallholder farmers is vulnerable to climate change and climate variability. Cropping intensity, the number of crops planted annually, can be used as a measure of food security for smallholder farmers given that it can greatly affect net production. Current techniques for quantifying cropping intensity may not accurately map smallholder farms where the size of one field is typically smaller than the spatial resolution of readily available satellite data. We evaluated four methods that use multi-scalar datasets and are commonly used in the literature to assess cropping intensity of smallholder farms: 1) the Landsat threshold method, which identifies if a Landsat pixel is cropped or uncropped during each growing season, 2) the MODIS peak method, which determines if there is a phenological peak in the MODIS Enhanced Vegetation Index time series during each growing season, 3 ) the MODIS temporal mixture analysis, which quantifies the sub-pixel heterogeneity of cropping intensity using phenological MODIS data, and 4) the MODIS hierarchical training method, which quantifies the sub-pixel heterogeneity of cropping intensity using hierarchical training techniques. Each method was assessed using four criteria: 1) data availability, 2) accuracy across different spatial scales (at aggregate scales $250 \times 250 \mathrm{~m}$, $1 \times 1 \mathrm{~km}, 5 \times 5 \mathrm{~km}$, and $10 \times 10 \mathrm{~km}$ ), 3) ease of implementation, and 4) ability to use the method over large spatial and temporal scales. We applied our methods to two regions in India (Gujarat and southeastern Madhya Pradesh) that represented diversity in crop type, soils, climatology, irrigation access, cropping intensity, and field size. We found that the Landsat threshold method is the most accurate $\left(R^{2} \geq 0.71\right.$ and RMSE $\left.\leq 0.14\right)$, particularly at smaller scales of analysis. Yet given the limited availability of Landsat data, we find that the MODIS hierarchical training method meets multiple criteria for mapping cropping intensity over large spatial and temporal scales. Furthermore, the adjusted $\mathrm{R}^{2}$ between predicted and validation data generally increased and the RMSE decreased with spatial aggregation $\geq 5 \times 5 \mathrm{~km}\left(\mathrm{R}^{2}\right.$ up to 0.97 and RMSE as low as 0.00$)$. Our model accuracy varied based on the region and season of analysis and was lowest during the summer season in Gujarat when there was high sub-pixel heterogeneity due to sparsely cropped agricultural land-cover. While our results specifically apply to our study regions in India, they most likely also apply to smallholder agriculture in other locations across the globe where the same types of satellite data are readily available.
\end{abstract}

(c) 2013 Elsevier Inc. All rights reserved.

\section{Introduction}

Smallholder farmers, who grow crops using low-intensity practices on small parcels of land (typically $\leq 2$ ha), comprise approximately $50 \%$ of rural populations in developing nations and contribute up to $90 \%$ of developing nations' staple food production (Morton, 2007; Singh et al., 2002). These smallholder farmers are particularly vulnerable to global and environmental change, including climate change and

\footnotetext{
* Corresponding author at: Dept. of Ecology, Evolution, and Environmental Biology, 10th floor Schermerhorn Extension, Columbia University, 1200 Amsterdam Avenue, New York, NY 10027, USA. Tel.: +1 5093968700.

E-mail addresses: mj2415@columbia.edu (M. Jain),pm2658@columbia.edu (P. Mondal),rd2404@columbia.edu (R.S. DeFries), csmall@columbia.edu (C.Small), ggalford@uvm.edu (G.L. Galford).
}

variability, falling water tables, and market volatility, because they typically do not have access to appropriate technologies to mitigate vulnerability, such as crop insurance, nutrient inputs, and capital for improved seed stock (Leichenko \& O'Brien, 2002; Lobell et al., 2008; Morton, 2007). This vulnerability results in high inter-annual variability in cropping practices of many smallholder farmers across the globe (O'Brien et al., 2004; Tao et al., 2006). In order for scientists and policymakers to develop and target effective strategies for farmers to cope with this variability, it is necessary to identify which farmers and agricultural regions are the most vulnerable to global and environmental changes. One important first step in doing this is to identify cropping patterns of smallholder farmers and determine how and why they change through time. Satellite image analyses offer a way to feasibly do this over large areas and in multiple regions across the globe (Brisco et al., 1998; Lobell et al., 2012; Thenkabail et al., 2012). 
Over the last several decades, many remote sensing approaches have been developed to identify cropping practices, such as crop type and cropping intensity (i.e. whether a farm is single, double, or triple cropped in a given year), across large spatial and temporal scales (e.g. Biradar \& Xiao, 2011; Collins, 1978; Quarmby et al., 1992; Xiao et al., 2005). However, current techniques may not be appropriate for mapping cropping practices of smallholder farms where a field is typically smaller than the spatial resolution of readily available satellite data such as MODIS (250 m resolution) and sometimes Landsat (30 m resolution). Identifying appropriate techniques to map smallholder farms is important, however, given that over 50\% of rural populations in developing nations are smallholder farmers who are particularly vulnerable to global and environmental change (Morton, 2007).

Previous methods have relied on high temporal-resolution datasets like MODIS to assess crop type and cropping intensity based on crop phenologies (e.g. Galford et al., 2008; Sakamoto et al., 2005; Wardlow et al., 2007). Vegetation index phenologies from MODIS have been used to detect crop type based on a crop's unique temporal signature (Macedo et al., 2012; Morton et al., 2006); this technique is especially powerful given that it is typically difficult to distinguish crops based purely on spectral signatures (Maxwell et al., 2004). For example, Sakamoto et al. (2009) found that rice can be accurately distinguished from other monsoon crops in South Asia based on the unique phenological signature of field flooding and rice transplanting early in the growing season. Phenologies have also been used to quantify the cropping intensity of an agricultural pixel by counting the number of peaks in a pixel's vegetation index time series (e.g. Biradar \& Xiao, 2011). While these studies offer the potential for MODIS to assess crop type and cropping intensity, the authors of these studies acknowledge that the reported high accuracy of these methods is due to the large size of the farms that were monitored; typically, individual farm plots in these studies spanned ten to fifteen MODIS pixels. It is unclear whether high accuracies will hold true for smallholder fields that are typically smaller than the size of one MODIS pixel and have highly heterogeneous cropping practices that may result in sub-pixel heterogeneity.

To overcome possible sub-pixel heterogeneity of MODIS pixels, other studies have used Landsat data to assess crop type and cropping intensity. Landsat images have a higher spatial resolution $(30 \mathrm{~m})$ that is more similar in size to an individual smallholder field. To identify crop type, unique spectral signatures that represent individual crops can be used to classify agricultural Landsat pixels (Ozdogan et al., 2006). The accuracy of this method, however, depends on several different factors. The crops to be mapped must have a detectable difference in spectral signatures, which becomes more difficult when crop types are from the same family and have similar flowering, heading, and leaf out signatures (Lobell \& Asner, 2004). In addition, Landsat images must be available at the appropriate time period during the crops' growth cycles when these key differences can be detected (Martínez-Casasnovas et al., 2005; Odenweller \& Johnson, 1984). To quantify cropping intensity, a season-specific Normalized Difference Vegetation Index (NDVI) threshold can be used to identify whether an agricultural pixel is cropped or uncropped in a given season (Lenney et al., 1996). This method, however, requires that at least one Landsat image is available during each of the growing seasons of interest. Due to the low temporal resolution of Landsat and its susceptibility to missing values due to cloud cover, the coverage required to assess crop type and cropping intensity is not assured in most agricultural regions across the globe, particularly in the tropics where there are often periods of intense cloud cover (Fang et al., 1998). Thus while Landsat offers improved spatial resolution over MODIS, it is possible that Landsat will not offer the necessary temporal resolution to assess crop type and cropping intensity.

Finally, several studies have attempted to quantify MODIS sub-pixel heterogeneity by using mixture models that identify the percent of each pixel that is under different cropping strategies. For example, Lobell and Asner (2004) identified the percent of each MODIS pixel that was under two different crop types by using a temporal mixture model where unique crop-specific phenologies were the defining end-members. This method had high accuracy $\left(\mathrm{R}^{2}>0.8\right)$ across the study region at coarse scales $\left(\geq 10 \mathrm{~km}^{2}\right)$, yet the accuracy of the method was greatly reduced $\left(\mathrm{R}^{2}=0.5\right)$ when assessing the mixture fraction of individual pixels $(250 \times 250 \mathrm{~m})$. This suggests that temporal mixture models may not be appropriate for a detailed understanding of sub-pixel heterogeneity at a localized scale.

A second mixture approach is to use hierarchical training techniques, where higher-resolution satellite data (e.g. Landsat) are used to identify the relationship between sub-pixel heterogeneity and the spectral signature of lower-resolution satellite data (e.g. MODIS; Dai \& Khorram, 1998; Braswell et al., 2003). The identified scaling relationship is then used to quantify the percent of each pixel that is comprised of different land-cover classes in the lower-resolution image. While this technique has shown promise in previous studies that map forest cover (e.g. Braswell et al., 2003), it is unclear how well this technique can be applied to agricultural regions with heterogeneous cropping patterns. In these regions, it may be difficult to quantify consistent and predictable scaling relationships between the lower and higher resolution spectral data.

The goal of this study is to apply each of the four broad techniques described above to map cropping intensity of smallholder farms in two study regions in India, and assess the benefits and problems with each method. These techniques have been shown to accurately map cropping patterns of medium to large scale farms, but it is unclear how well they assess cropping intensity of smallholder farms ( $\leq 2$ ha). Our study focuses only on mapping cropping intensity and not crop type given that cropping intensity is a critical factor for production as well as food security of smallholder farmers, and is highly sensitive to inter-annual rainfall and irrigation availability (Mahtab \& Karim, 1992; Pretty et al., 2003). Furthermore, it will be difficult to assess crop type in our study region due to the high heterogeneity in crops planted across agricultural fields (Jain, unpublished data). We chose India to assess the feasibility of mapping cropping intensity because over $50 \%$ of the population is smallholder farmers, a majority of the land use is agriculture, and previous studies have shown that food production in this region is particularly variable with climate, making it one of the most important areas to map accurately (Foster \& Rosenzweig, 2004; Lobell et al., 2008). Given that agricultural practices are highly variable throughout the country and range from nearly subsistence to highly commercial cash crop production, we selected study regions in the states of Madhya Pradesh and Gujarat that represent these two extremes.

Using data for the cropping season from 2009 to 2010, we compare four methods: 1) the Landsat threshold method, which identifies if a Landsat pixel is cropped or uncropped during each growing season, 2 ) the MODIS peak method, which determines if there is a phenological peak in the MODIS Enhanced Vegetation Index (EVI) time series during each growing season, 3 ) the MODIS temporal mixture analysis (TMA), which quantifies the sub-pixel heterogeneity of cropping intensity by conducting a TMA of phenological data, and 4) the MODIS hierarchical training method, which quantifies the sub-pixel heterogeneity of cropping intensity using hierarchical training techniques (Fig. 1; Section 2.3). The results of each model were validated and compared using higher-resolution Quickbird, WorldView-2, or Google Earth and Landsat imagery, which represented ground-truth data of cropped versus uncropped farms (Section 2.4). We then assessed the generalizeability of our techniques by applying each of our four methods to a new region within the same agro-ecological zone for each of our study regions. We assessed each method's accuracy in this validation region to ensure that our methods are applicable over larger areas than simply the region used to train our four models (Section 2.5). Finally, we assessed the overall utility of each method based on multiple criteria (DeFries \& Chan, 2000): 1) the availability of data, 2) the accuracy of the method (at aggregate scales of $250 \times 250 \mathrm{~m}, 1 \times 1 \mathrm{~km}, 5 \times 5 \mathrm{~km}$, and $10 \times 10 \mathrm{~km}), 3$ ) the ease of implementation, and 4) the ability to use the method over large spatial and temporal scales. By comparing these 


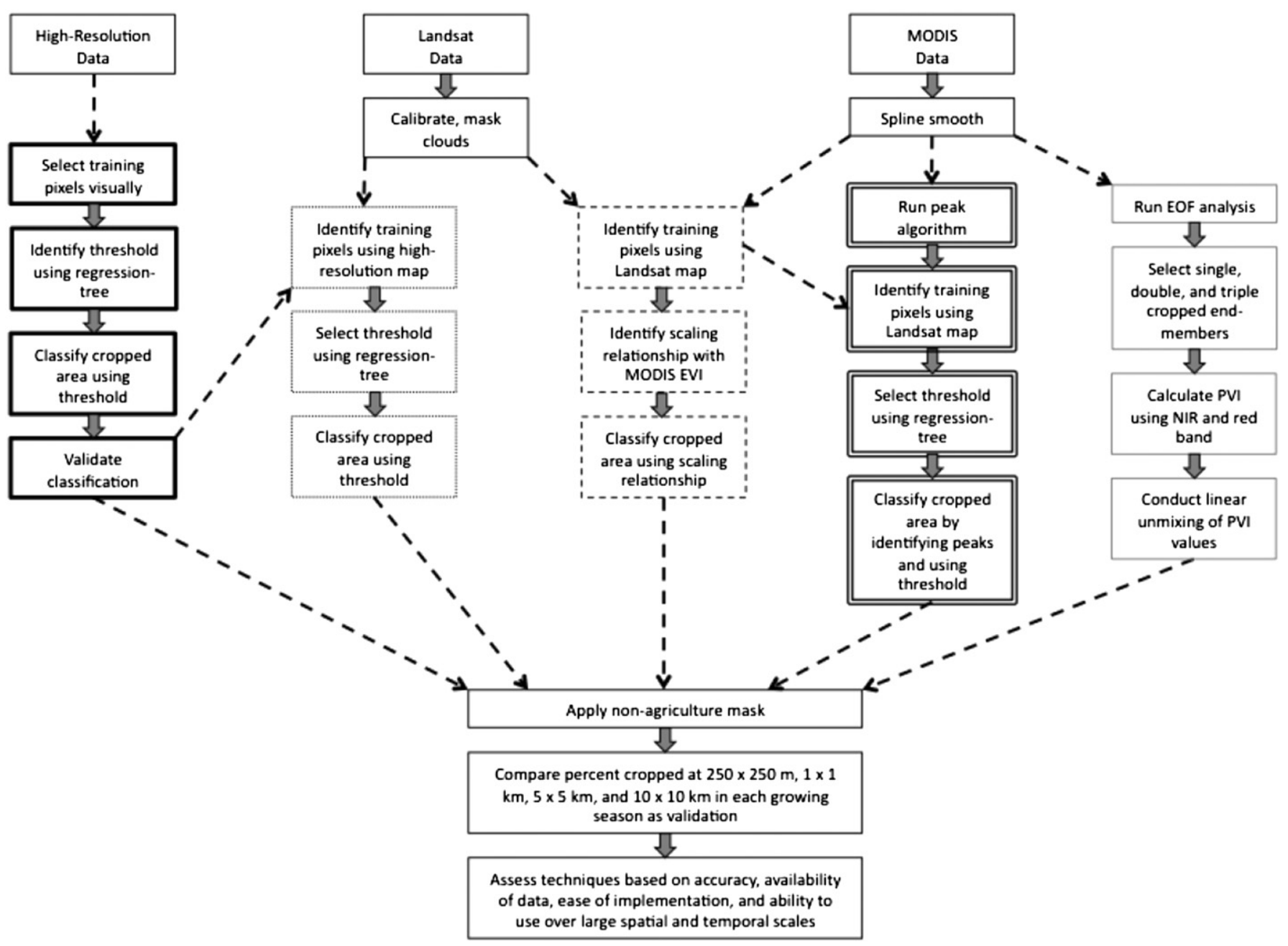

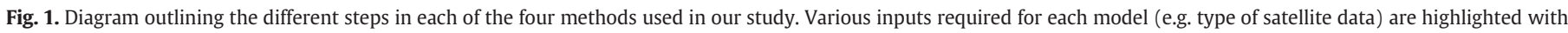

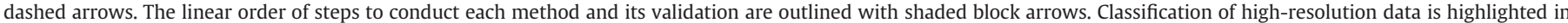

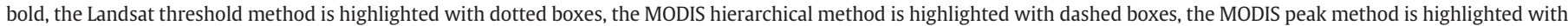
double line boxes, and the MODIS Temporal Mixture Analysis (TMA) is highlighted with gray boxes.

four techniques, our study identifies which methods meet our four criteria for mapping cropping intensity of smallholder farms. While our results specifically apply to our study regions in India, they most likely also apply to smallholder agriculture in other locations across the globe where the same types of satellite data are readily available.

\section{Methods}

\subsection{Study sites}

There is a large amount of diversity in cropping pattern across all of India due to factors such as climate, soil type, irrigation access, and market dependence (Fan et al., 2000; Gajbhiye \& Mandal, 2000; O'Brien et al., 2004). To represent this diversity, we selected two regions in India: one in the arid to semi-arid agro-ecological zone of Northwest India (central Gujarat) and one in the sub-tropical agro-ecological zone of central India (eastern Madhya Pradesh, Fig. 2; Gajbhiye \& Mandal, 2000). Both regions are primarily comprised of smallholder agricultural land-cover. Central Gujarat has low annual rainfall (approximately $300 \mathrm{~mm}$ per year), has predominantly sandy to loamy soils, has high access to irrigation (via groundwater or surface canals), and is very market-oriented (Dubash, 2002; Gajbhiye \& Mandal, 2000; IRI/LDEO Climate Data Library, 2012). In contrast, the site in central India receives more annual rainfall ( $1050 \mathrm{~mm}$ per year), has predominantly loamy to clayey red and black soils, has little access to irrigation, and agriculture is primarily composed of staple crops (e.g. rice and wheat) that are used for local consumption and local markets (Gajbhiye \& Mandal, 2000; Indiastat, 2012; IRI/LDEO Climate Data Library, 2012). An algorithm that works well in both regions is likely an appropriate method to map cropping intensity of smallholder farms across an array of regions with diverse climatic patterns, soil types, irrigation access, and crop types.

In both regions, there are three possible growing seasons: the monsoon season (kharif) that spans from June until late October, the winter season ( $\mathrm{rabi}$ ) that spans from November until late March, and the summer season (garmi) that spans from April to late May (Ministry of Agriculture, 2010). The primary winter crops in Gujarat (e.g. wheat and groundnut) and Madhya Pradesh (e.g. wheat, sorghum, pulses, and mustard) are planted as late as November and harvested as early as February (Ministry of Agriculture, 2010). Thus remote sensing imagery from late December to January should capture all winter crops during their peak growth period before harvest. The primary summer crops in Gujarat (e.g. sorghum) are planted as late as February and harvested as early as May (Ministry of Agriculture, 2010), making April an ideal time for remote sensing imagery to capture all sown summer crops before harvest (Fig. 3). The monsoon is the main source of rainfall in both regions, and this rainfall usually lasts from June until mid-September, though off-season precipitation occasionally falls in December to January (Gadgil, 2003; IRI/LDEO Climate Data Library, 2012). For farmers to plant an additional crop in the winter or summer seasons, they must have access to irrigation or the soils must be able to 

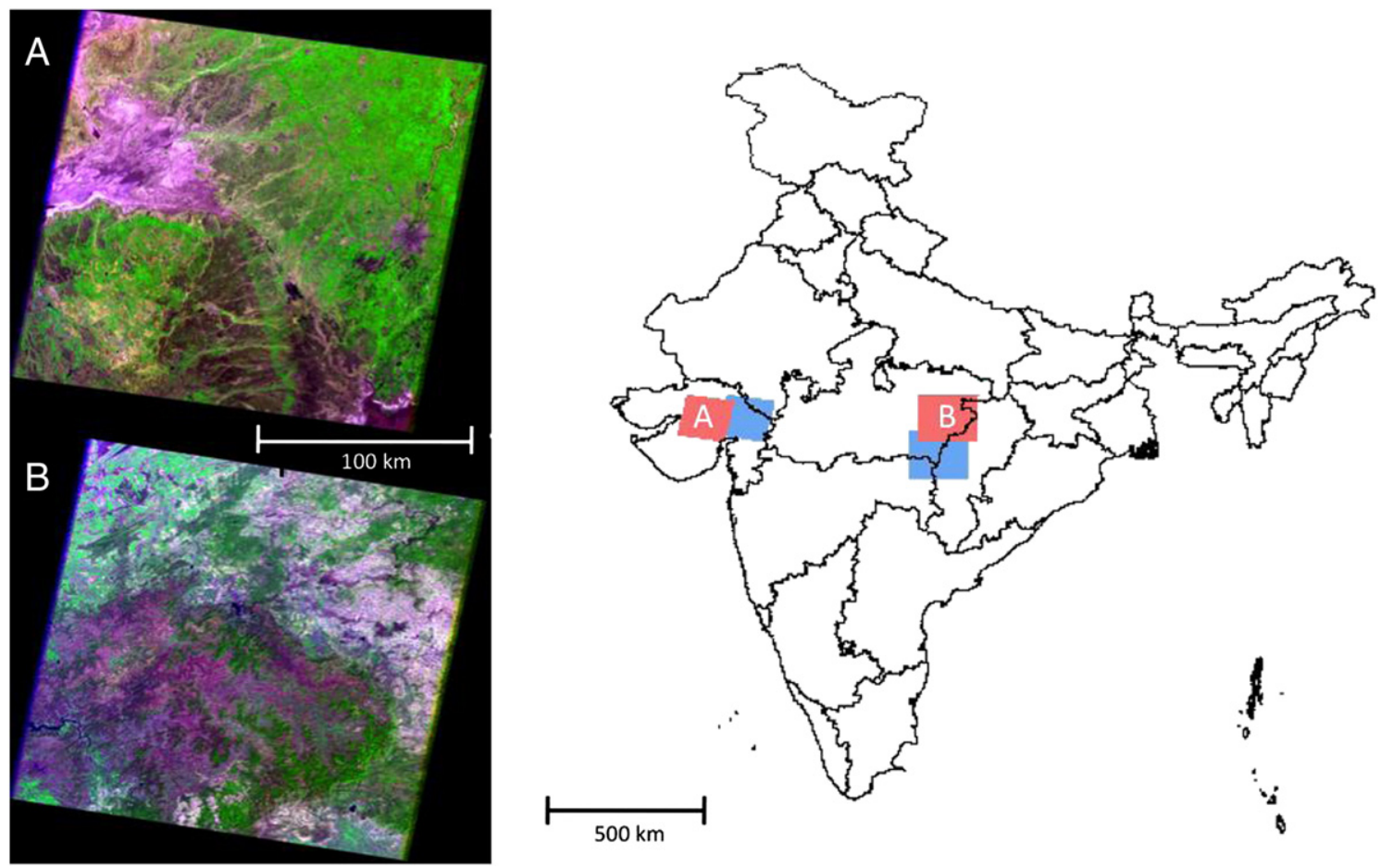

Fig. 2. The coverage of our two study areas in India (Landsat scenes used for original analysis are highlighted in red while Landsat scenes used for the reproducibility test are highlighted in blue). The Gujarat site (Path 149, Rows 44 and 45) represents an agricultural region that has low annual rainfall, has high access to irrigation, and is very market-oriented. The Madhya Pradesh site (Path 143, Rows 44 and 45) represents an agricultural region that has higher annual rainfall, has varied access to irrigation, and grows crops for subsistence or local markets. The false color composites ( $R=$ band 3, G = band 4, and B = band 2) of the original Landsat scenes for Gujarat (A) and Madhya Pradesh (B) are shown for winter 2009 - 2010.

store water from the monsoon or non-seasonal rains (Dubash, 2002; Narain \& Roy, 1980). In our Gujarat site, our observations and information from farmers indicate all farms are cropped in the monsoon season and, due to high irrigation access, many farms are additionally cropped in the winter and summer seasons (Jain, unpublished data). In our Madhya Pradesh site, our observations suggest that nearly all farms are cropped during the monsoon season, some farms are cropped during the winter season, and even fewer farms are cropped in the summer season due to low access to irrigation (DeFries, personal observation). Furthermore, given that irrigation access is not consistent over time and space in both regions, there is high heterogeneity in cropping intensity across farms, which may result in sub-pixel heterogeneity at the MODIS scale.

\subsection{Mask}

We created a mask to eliminate non-agricultural pixels, including scrubland, forests, bare fields, and urban areas, from all of our analyses. The random forest classification algorithm (Breiman, 2001) was used to differentiate between agricultural and non-agricultural land-cover classes, and this analysis was run independently in each of our two study regions. We used only MODIS-derived variables in our random forest classifier based on the premise that a MODIS-derived mask has better applicability over large scales than a Landsat-derived mask given that Landsat scenes must be calibrated and mosaicked when used over large areas (Canty \& Nielsen, 2008). For our MODIS phenological variables, we downloaded EVI data as well as the individual blue,

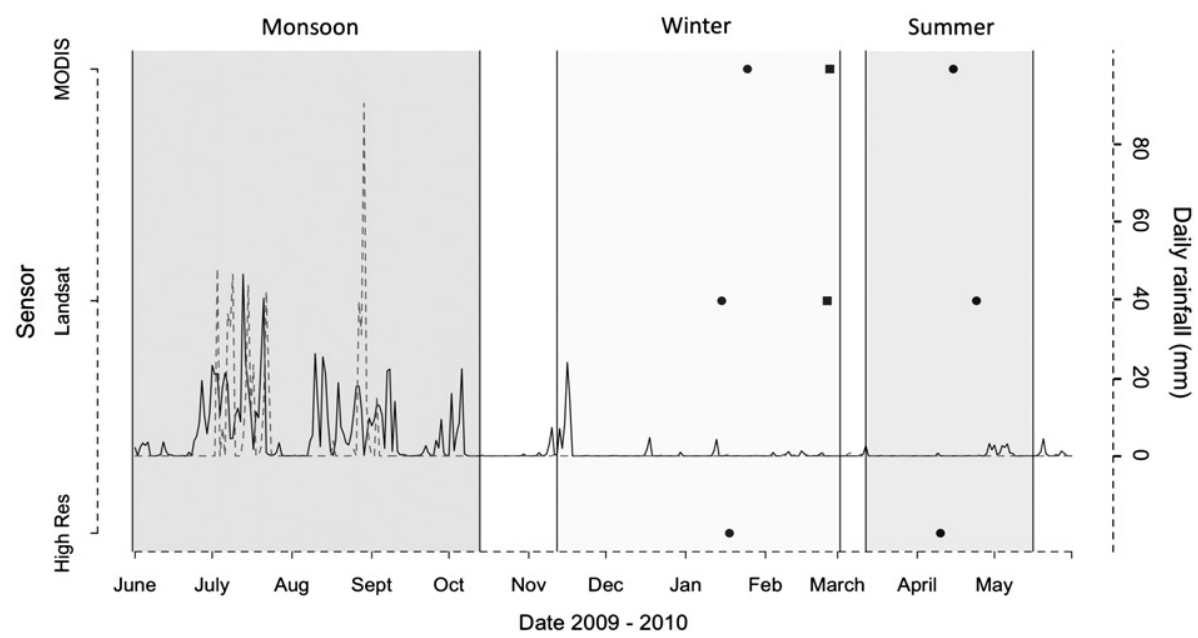

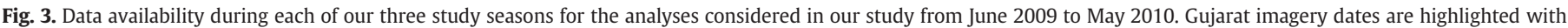

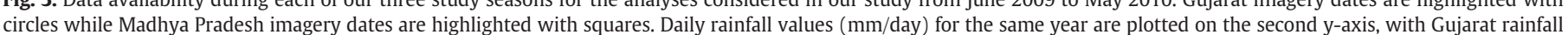
represented in a gray dashed line and Madhya Pradesh rainfall represented in a black solid line. 
red, near-infrared (NIR), and mid-infrared (MIR) bands at $250 \mathrm{~m}$ resolution (blue and NIR products were down-sampled from $500 \mathrm{~m}$ observations). All MODIS data were downloaded as sixteen-day composites during the length of our study period from 2009 to 2010. The following variables were inputted into our random forest classifier: mean EVI, the standard deviation of the EVI phenology, the minimum value in the EVI phenology, the maximum value in the EVI time series, mean blue, mean red, mean NIR, and mean MIR. For training data, we used a total of 700 points in the two study regions that represented the major land-cover classes in each region; these data were collected using visual interpretation of Google Earth imagery (Version 6.1.0.5001, 2012 was used for all analyses) from the date that was closest to our study period. We validated our random forest model using 550 additional points from Google Earth and mask accuracy was relatively high in both regions (overall accuracy $\geq 77 \%$; see Table S1 in the Supplementary Data). It is important to note that we erred on the side of omission rather than commission so that we were more certain that the pixels considered in our study were agricultural land-cover. We then applied our mask to each high-resolution, Landsat, and MODIS image before conducting further analyses. We applied the $250 \mathrm{~m} \times 250 \mathrm{~m}$ MODIS mask to higher spatial resolution Landsat and Quickbird imagery by downscaling the MODIS pixels to $30 \times 30 \mathrm{~m}$ and $2.4 \times 2.4 \mathrm{~m}$ respectively. If a downscaled pixel was partially assigned a mask value (partial assignments occur given that $250 \times 250 \mathrm{~m}$ pixels are not divisible by $30 \times 30 \mathrm{~m}$ and $2.4 \times 2.4 \mathrm{~m}$ respectively), the pixel was assigned as masked.

To assess whether mask accuracy was influencing our results, we created a higher accuracy mask using Landsat data for our study region in Gujarat and reassessed our models for the winter season. We find that the results from our model comparison are consistent when using this higher accuracy mask (Table S2), suggesting that mask accuracy does not strongly influence our results. The total cultivated area calculated by our four models, however, will be dependent on the accuracy of the mask. Masks with high omission rates will omit agricultural pixels and therefore under report cropped area, and masks that have high commission with other green vegetation, like forests, will likely over report cropped area.

\subsection{Methods to map cropping intensity}

We compared four techniques to quantify the cropping intensity of smallholder agriculture in our two study regions, which are each the size of one Landsat scene (Fig. 2). We ran our analysis for the winter and summer seasons in the Gujarat site, and the winter season in the Madhya Pradesh site. We did not run our analyses for the monsoon season in both regions since appropriate high-resolution and Landsat imagery were unavailable due to high cloud cover, and for the summer season in Madhya Pradesh given that few crops were planted in this season due to little irrigation access. This resulted in three separate study seasons: the winter and summer seasons in Gujarat, and the winter season in Madhya Pradesh. We aimed to assess the amount of cropped area only in specific season years when Landsat data were available for our two study regions.

Each method quantifies the fraction of each agricultural pixel that is cropped or uncropped in each of the study seasons. Given that we applied a high-accuracy mask to remove non-agricultural pixels, we assume that uncropped areas in our estimates represent fallow agricultural fields. For the seasons that we did not run analyses, we made two assumptions based on our field observations: 1) all agricultural pixels in both sites were cropped during the monsoon season given the ability to plant crops solely based on rainfall, and 2) no agricultural pixels were cropped during the summer season in the Madhya Pradesh site given little irrigation access.

\subsubsection{Landsat threshold method}

Our Landsat threshold method (Fig. 1, dotted line boxes) identified whether an agricultural pixel was cropped or uncropped in each study season at a $30 \mathrm{~m}$ resolution. We downloaded available cloud-free Landsat imagery ( $0 \%$ cloud cover in the archive registry) that corresponded with each study season from 2009 to 2010 from the United States Geological Service (USGS) EarthExplorer database. When possible, we downloaded Landsat 5 TM imagery because Landsat 7 ETM + imagery were incomplete during our study period due to problems with scan line correction. One Landsat scene encompassed our study region in Gujarat (Path: 149, Row: 44) and one scene represented our study region in Madhya Pradesh (Path: 143, Row: 44). Landsat images were converted to spectral radiance based on each image's acquisition date and sun elevation using ENVI's built-in Landsat calibration function. We then calculated the NDVI of all agricultural pixels in our image since previous studies have shown a high correlation between NDVI and the photosynethic biomass of cropped fields (Benedetti \& Rossini, 1993; Fuller, 1998). NDVI was calculated using the NIR (band 4) and red (band 3) band for both Landsat 5 TM and Landsat 7 ETM + imagery.

We identified twenty-five homogenous regions of interest that were cropped and twenty-five homogeneous regions of interest that were uncropped using visual interpretation of high-resolution satellite imagery (i.e. Quickbird, WorldView-2, and Google Earth). Regions of interest ranged from $500 \times 500 \mathrm{~m}$ to $5 \times 5 \mathrm{~km}$ in size. We then extracted NDVI values for the associated pixels in the Landsat imagery, which we used as training pixels $(n \geq 300)$ in a regression tree to identify the NDVI value that best differentiated between cropped versus uncropped agricultural pixels. Regression tree analyses were done separately for each study season, and identified thresholds had high accuracy (>99\%) in predicting cropped versus uncropped agriculture. We finally applied the NDVI threshold identified for each season to the appropriate Landsat scene to classify the remainder of pixels as cropped or uncropped agriculture. The details of all analysis software for all methods are outlined in Table S3 in the Supplementary Information. In addition, all threshold values for all methods are listed in Table S4 in the Supplementary Information.

\subsubsection{MODIS peak method}

For the MODIS peak method (Fig. 1, double lined boxes), we used two criteria to identify whether a MODIS $250 \times 250 \mathrm{~m}$ pixel was cropped in each study season: 1 ) whether there was a peak in the EVI phenology during the season of interest, and 2) if this peak EVI value exceeded a threshold that represented cropped agriculture. We downloaded data for two MODIS tiles, one for our study region in Gujarat (h24v06) and one for our study region in Madhya Pradesh (h25v06), from January 2001 to December 2011. The data are 16-day composites of the LandDAAC MODIS version 5 EVI product downloaded from the IRI/LDEO Climate Data Library. These data were originally compiled from the USGS. By compositing only the clearest, most cloud-free daily values over a 16-day period, this product offers relatively cloud-free images (Huete et al., 2002). We use EVI, a measure of photosynthetically active vegetation, to detect crop growth in a given pixel throughout the entire growing season (Sims et al., 2006). We use EVI rather than NDVI because it better corrects for atmospheric contamination by incorporating the blue band in its calculation, and is less likely to become saturated at high-levels of biomass given that it better adjusts for background soil and canopy reflectance (Huete et al., 1997). In order to correct for any remaining high-frequency noise, we smoothed our time series using a cubic smoothing spline function (Fig. 4).

To detect if there was a peak in vegetation growth during the season of interest, we identified whether a given EVI value was higher than both of its immediate neighbors in the vegetation index time series (Fig. 5). A peak in the EVI time series represents the phase in a crop's growth cycle when vegetation cover is highest prior to senescence and crop harvest (Sakamoto et al., 2010). If a peak was identified in the time series, we then determined if the EVI value for the date closest to the date of our Landsat imagery was above a threshold that identified cropped agriculture. If the EVI value was less than this threshold, the 
pixel was assumed to be a non-agricultural land-cover class that was inaccurately classified in our initial random forest mask (see Section 2.2). To calculate this threshold, we collected twenty-five regions of interest each for cropped and uncropped agriculture across each study region through visual interpretation of our Landsat classified images (Section 2.3.1). Regions of interest ranged from $500 \times 500 \mathrm{~m}$ to $5 \mathrm{~km} \times 5 \mathrm{~km}$. All training pixels in the Landsat imagery were homogeneous enough to avoid spectral mixing of cropped with uncropped regions in the associated MODIS pixels. We then extracted the EVI value for the date closest to the date of our Landsat imagery for the associated MODIS pixels and used them to identify a threshold for cropped agriculture, which was calculated using the same methods described for the Landsat threshold method (Section 2.3.1).

\subsubsection{TMA}

The MODIS TMA (Fig. 1, gray boxes) identified the percent of each MODIS pixel $(250 \times 250 \mathrm{~m}$ resolution $)$ that was single, double, or triple cropped based on a TMA of end-member phenologies that represent each of these three classes. To select appropriate end-members, we conducted an empirical orthogonal fractions (EOF) analysis by running a Principal Component Analysis (PCA) on our entire MODIS EVI time series from 2001 to 2011 (Small, 2012). We attempted the same analysis using MODIS data that only spanned the time period of our case study, 2009 to 2010, but found that it was difficult to select appropriate end-members due to increased variability in phenologies across our dataset. In order to identify the temporal end-members that best represented our temporal feature space, we examined the two-dimensional plots of each of the first three PCA bands, which represented over $90 \%$ of the variance in our dataset. We linked the maps produced by our PCA analysis with our original EVI time series data and, based on visual interpretation, selected single end-member EVI phenologies that were most representative of bare ground, as well as single, double, and triple cropping (Fig. 6A). At the regional scale, our end-members were very stable, which allowed us to use a single phenology as an end-member. We included bare ground as an endmember phenology to account for possible pixels that were misclassified using our random forest mask (Section 2.2).

EVI does not scale linearly in a TMA since it is a ratio. We instead calculated the simple Perpendicular Vegetation Index (PVI), which is a linear combination of the NIR and red band (Lobell \& Asner, 2004; Richardson \& Weigand, 1977).

simple PVI $=$ NIR - red

We subsetted each PVI time series for the selected end-members to span from 2009 to 2010. We then used these four end-member PVI phenologies in our TMA to identify the percent of each MODIS pixel that was bare ground or single, double, or triple cropped (Fig. 6B). Single cropping denoted pixels that were cropped only during the monsoon season, double cropping denoted pixels that were cropped in both the monsoon and winter seasons, and triple cropping denoted pixels that were cropped in all three growing seasons (Fig. 6A). These TMA analyses were conducted separately for each of the two study regions.
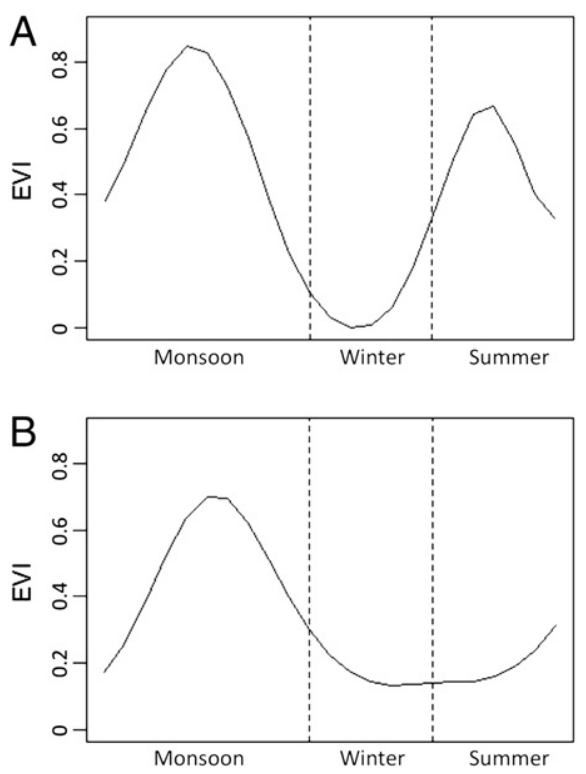

Fig. 5. Spline-smoothed EVI time series during our study period (2009 - 2010) from two agricultural pixels in our Gujarat site. In the first panel $(A)$, there are two peaks suggesting that the pixel was cropped during the monsoon and summer seasons. In the second panel (B), only one peak exists suggesting that this pixel was only cropped during the monsoon season. After identifying whether there was a peak or not during each growing season, we then applied a threshold method that identified if the peak EVI value was greater than the threshold that identified cropped area. For all seasons, this threshold value was 0.6 or lower suggesting that all peaks in these time series represent cropped agricultural pixels.

\subsubsection{Hierarchical training technique}

The hierarchical training technique (Fig. 1, dashed line boxes) quantified the percent of each MODIS pixel $(250 \times 250 \mathrm{~m}$ resolution $)$ that was cropped in each season by calibrating MODIS EVI values to the percent of each pixel cropped as defined using higher resolution ground-truth imagery. Quickbird and Worldview-2 imagery were used as ground-truth data for our Gujarat site and Landsat imagery was used as ground-truth data for our Madhya Pradesh site. To calculate the calibration algorithm, we selected random MODIS pixels across the region that overlapped with our higher resolution calibration data and extracted the EVI value from the date closest to that of the calibration data for each pixel. Next, we calculated the true percent that each of these MODIS pixels was cropped using our higher resolution ground-truth imagery. We checked that the relationship between MODIS EVI and the percent that each MODIS pixel was cropped was linear for each of our analyses, and used linear regressions to calculate the appropriate slope and intercept to calibrate our EVI values. Five hundred random pixels were used in Gujarat and 1500 random pixels were used in Madhya Pradesh to establish a consistent calibration algorithm. These analyses were independently conducted for each scale of aggregation (i.e. $250 \times 250 \mathrm{~m}, 1 \times 1 \mathrm{~km}, 5 \times 5 \mathrm{~km}$, and $10 \times 10 \mathrm{~km}$ ) and each study season.

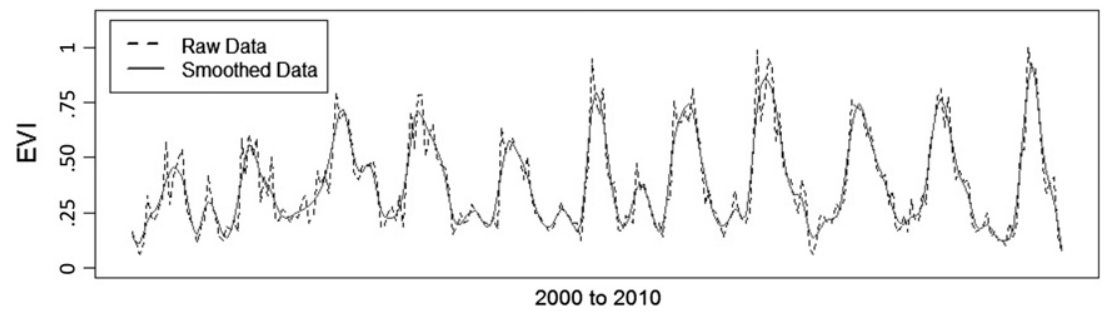

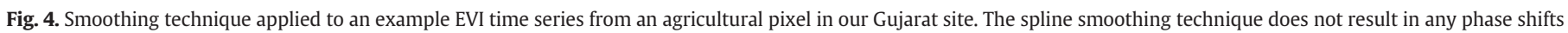
and only removes large peaks within the dataset that are likely due to cloud cover or other high-frequency noise. 

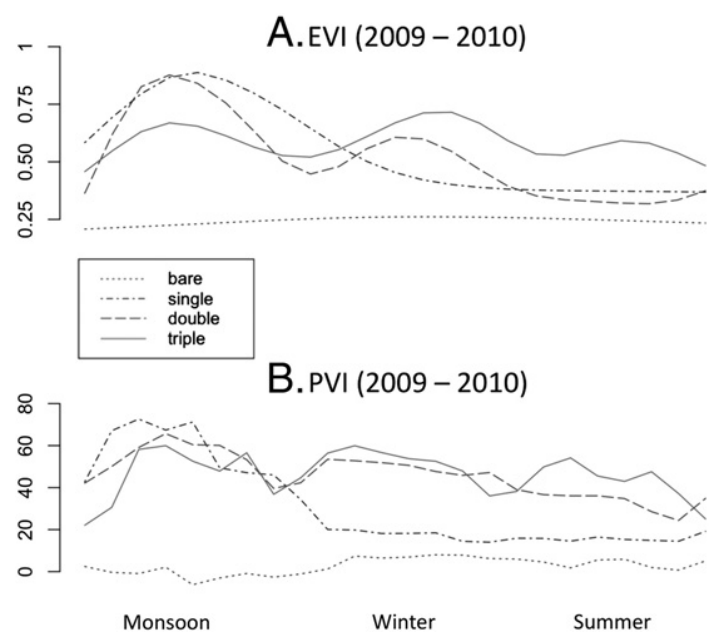

Fig. 6. End-member phenologies used for our Temporal Mixture Analysis (TMA) in Gujarat. Panel A represents EVI end-members for bare ground (dotted line), single crop (dot-dash line), double crop (dashed line), and triple crop (solid line), which are plotted for the time period of our analysis (June 2009 to 2010). The same end-member pixels' PVI values are plotted in Panel B, which were the actual phenologies used as end-members in the TMA.

\subsection{Validation techniques}

To validate each of our four models and assess their accuracy in mapping cropping intensity, we compared cropped area using our four methods (Section 2.3; dependent variables) with cropped area defined using higher-resolution Quickbird, WorldView-2, or Landsat ground-truth imagery (independent variables; Fig. 8). Higher-resolution imagery served as ground-truth data for our study regions since it is possible to visually interpret whether a given field is cropped or uncropped (Fig. 7). Accuracy was assessed using root mean square error (RMSE), adjusted $\mathrm{R}^{2}$, and the Spearman's rank correlation coefficient. Furthermore, since previous studies (e.g. Lobell \& Asner, 2004; Potgieter et al., 2007) have suggested that the accuracy of crop classification algorithms varies based on the spatial aggregation used for analysis, we assess the accuracy of our four techniques at four different levels of aggregation: $250 \times 250 \mathrm{~m}, 1 \times 1 \mathrm{~km}, 5 \times 5 \mathrm{~km}$, and $10 \times 10 \mathrm{~km}$. While we expect the accuracy of our methods to increase with spatial aggregation due to the "averaging out" of errors, we are interested in identifying the lowest spatial scale at which this occurs and leads to relatively high accuracy in detecting cropped area for each of our methods.

\subsubsection{Validation imagery}

As validation data, we downloaded high-resolution Quickbird or Worldview-2 imagery (1.8 to $2.4 \mathrm{~m}$ resolution) if available during the peak growth period for each of our study seasons in 2009-2010: December to January for the winter season and April to May for the summer season. Overall one Quickbird image (2.4 m resolution) and two WorldView-2 images ( $1.84 \mathrm{~m}$ resolution) from the NASA Cad4nasa database met these criteria. These high-resolution data were visually inspected to identify whether a given agricultural pixel was cropped or uncropped at the time of acquisition (Fig. 7). For each image, we then selected twenty-five cropped and twenty-five uncropped regions of interest, which were each approximately $100 \times 100 \mathrm{~m}$, extracted the NDVI values for the associated pixels, and identified a threshold for cropped agriculture using the methods described for the Landsat threshold method (Section 2.3.1).

High-resolution data was obtained for the winter and summer seasons in Gujarat, however, we could not obtain cloud-free high- resolution data for the winter season in Madhya Pradesh. In this case, we used the classified Landsat map produced using the Landsat threshold method (Section 2.3.1) to validate our MODIS-derived models. While inferior to high-resolution data, Landsat is an alternative and has high accuracy for mapping cropped area $\left(\mathrm{R}^{2} \geq .71\right.$; Table 1$)$.

\subsubsection{Validation at different spatial scales of aggregation}

Given the differences in validation imagery available for our two study regions, we conducted two sets of validation analyses. For Gujarat, where high-resolution Quickbird and WorldView-2 imagery were available, we conducted validation at three levels of aggregation: $250 \times 250 \mathrm{~m}, 1 \times 1 \mathrm{~km}$, and $5 \times 5 \mathrm{~km}$. Since high-resolution data were unavailable for Madhya Pradesh, we also conducted validation using Landsat imagery as ground-truth data for both of our study sites. For these analyses, we conducted validation at three levels of aggregation: $250 \times 250 \mathrm{~m}, 1 \times 1 \mathrm{~km}$, and $10 \times 10 \mathrm{~km}$. The largest scale of aggregation used for high-resolution Quickbird and WorldView-2 imagery was only $5 \times 5 \mathrm{~km}$ and not $10 \times 10 \mathrm{~km}$ because our highresolution imagery had a smaller spatial extent than our Landsat validation imagery.

Validation was conducted in an automated manner by selecting five hundred MODIS pixels at random from the maps produced by the four methods as well as the validation imagery. By doing this, we can compare the fraction of area cropped in a $250 \times 250 \mathrm{~m}$ region predicted by our different methods (Section 2.3; dependent variables) and the true fraction of area cropped defined by the validation data (Section 2.4.1; Quickbird, WorldView-2, or Landsat used as independent variables). Cropped area estimates may range from $0 \%$ to $100 \%$ of a $250 \times 250 \mathrm{~m}$ region. The same random point selection algorithm was used for validation at larger scales of aggregation, however, the regions of interest in these cases were $1 \times 1 \mathrm{~km}, 5 \times 5 \mathrm{~km}$, and $10 \times 10 \mathrm{~km}$ respectively. At these larger scales of aggregation, cropped area estimates may range from $0 \%$ to $100 \%$ of a $1 \times 1 \mathrm{~km}, 5 \times 5 \mathrm{~km}$, or $10 \times 10 \mathrm{~km}$ region respectively. We aggregated to each spatial resolution by calculating the mean value within each desired grid cell (Butler, 1999).

To assess accuracy, we calculated the RMSE, the adjusted $R^{2}$ and the slope of the relationship (Table S5A and B), and the Spearman's rank correlation coefficient when comparing area cropped predicted by each of our methods and true area cropped as defined using our validation imagery. The RMSE identifies how closely points lie along the one to one line between our model results and validation data, whereas the adjusted $R^{2}$ is a measure of variance explained by each model. We also calculated the Spearman's rank correlation coefficient, which is a non-parametric test that is less sensitive to outliers. Validation was conducted for each scale of aggregation and each study season. The most accurate method was the one with the lowest RMSE as well as the highest adjusted $\mathrm{R}^{2}$ and Spearman's coefficient. In cases where a single method did not meet all three criteria ( 5 out of 24 cases), we selected the most accurate method as follows. First, we considered only the RMSE value; if a method's RMSE was greatly lower than the next best RMSE ( $>0.05$ difference), this method was considered to be the most accurate. Out of all three metrics that we considered, we are most interested in accuracy with respect to the RMSE since this measure is the most dependent on whether our predicted cropped area results match our validation values (as opposed to these values simply being correlated). In cases where the RMSE of two methods were within 0.05 of one another, we selected the method that had the higher adjusted $\mathrm{R}^{2}$ value (4 out of 24 cases).

To identify if our model results were biased at any particular range of cropped area, we conducted additional validation that statistically compared predicted cropped area from our four models with cropped area derived using our validation data. We did this by binning our cropped area estimates from the validation data by quartiles (i.e. cropped area $<25 \%, 25-50 \%, 50-75 \%$, and $>75 \%$ ) and then assessed whether our models were significantly under or over-predicting cropped area in each quartile by using paired Wilcoxon signed-rank tests (Mayer \& 

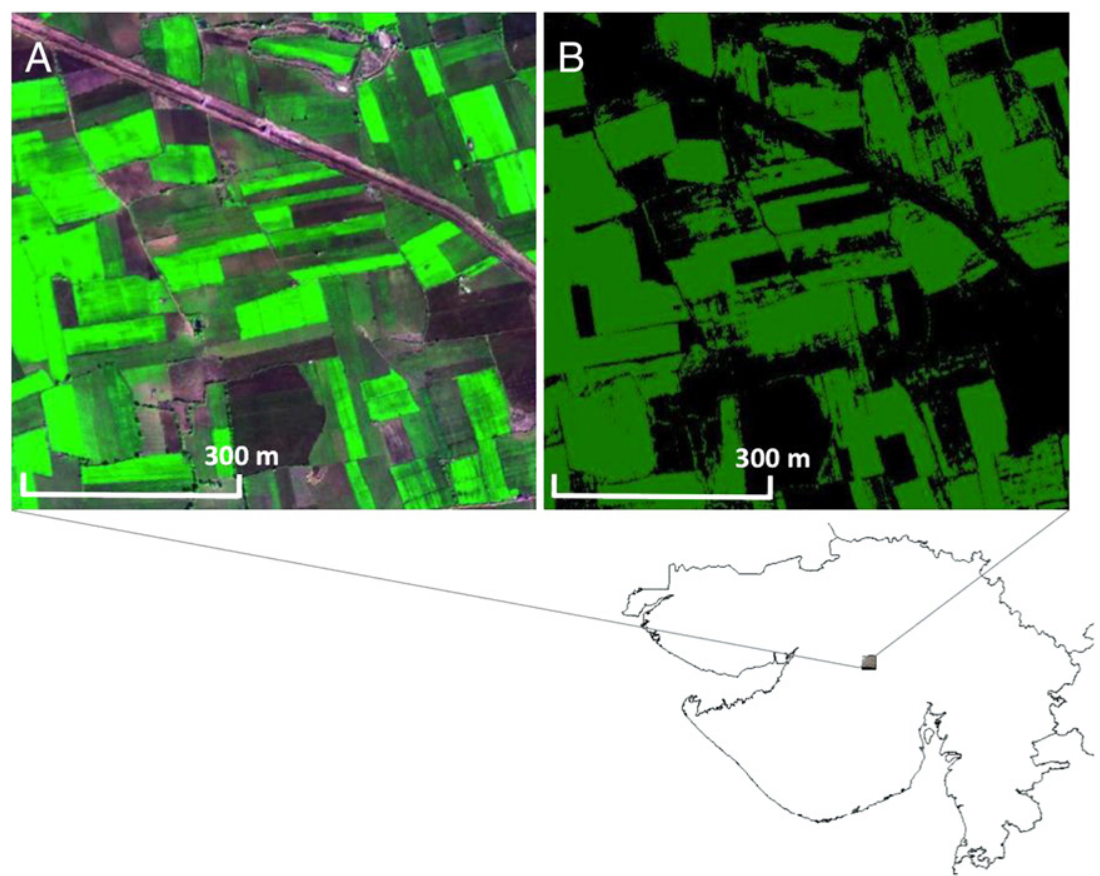

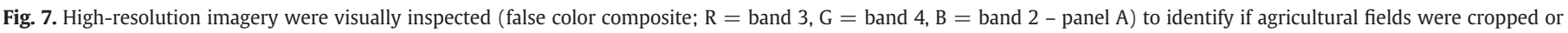

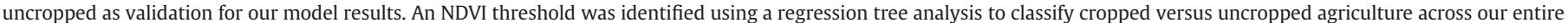
high-resolution image (classified map - panel B). This threshold was separately calculated for each study region during each growing season of interest.

Butler, 1993). This test is ideal given that comparisons are made in a pairwise fashion and do not assume normality, which is unlikely in this case given that the data are percentage estimates. Results of this analysis are reported in the Supplementary Information (Tables S6A and B).

\subsection{Reproducibility of techniques}

To assess whether our four methods (Section 2.3) were applicable to a wider region than only the area used to train our models, we validated our methods within the same agro-ecological zone (Gajbhiye \& Mandal, 2000) for our two study sites using a neighboring Landsat scene (Fig. 2; Gujarat: Row 148, Path 44; Madhya Pradesh: Row 143, Path 45). We conducted this additional analysis only for the winter season, given that this was the only season for which we had highresolution Quickbird and Worldview-2 data in the Gujarat site. For the Madhya Pradesh site, we used Landsat imagery for validation since no high-resolution Quickbird and Worldview-2 scenes were available. We validated our methods at multiple scales of aggregation $(250 \times 250 \mathrm{~m}, 1 \times 1 \mathrm{~km}, 5 \times 5 \mathrm{~km}$, and $10 \times 10 \mathrm{~km})$ using the methods described in Section 2.4. Since Landsat 7 ETM + imagery was the only cloud-free Landsat scene available for the Gujarat site, we masked pixels with missing values caused by the Landsat scan line correction problem in all imagery prior to validation. This ensured that our datasets were comparable despite the missing data pixels in the Landsat 7 ETM + imagery.

\subsection{Validation with Indian Agricultural Census data}

As a second method of validation, we compared cropped area estimates with Indian Agricultural Census data (from the Agricultural Census Division, Ministry of Agriculture, 2010) for several districts during the winter 2010 season. Due to the large scale of this analysis, we calculated cropped area using the methods derived for the $10 \times 10 \mathrm{~km}$ aggregation only. Since our original Landsat scene in each study region did not encompass any individual districts fully, we mosaicked results produced for our original study regions with results produced for our validation study regions. These larger study areas covered three districts in Gujarat and two districts in Madhya Pradesh. We did not consider the results of our summer season analysis given that agricultural census data does not exist for this season.

\subsection{Assessment of each method}

We used four criteria to assess the benefits and problems with each of our methods for quantifying cropping intensity: 1) data availability, 2) assessment accuracy, 3) ease of implementation, and 4) applicability over large spatial and temporal scales. For each criterion of interest, we subjectively assigned each method a rating as high performance (meaning that the method performed very well), moderate performance (method performed acceptably well), or low performance (method performed poorly). We assessed each method based on our experience using the methods in our two study regions. It is possible that our methods perform well regarding some criteria but poorly for other criteria. We discuss these criteria in addition to accuracy because different algorithms may be more appropriate in different situations depending on the main criteria of interest for a given study (DeFries \& Chan, 2000).

\section{Results}

\subsection{Accuracy of crop mapping methods compared to ground-truth validation imagery}

Of the four methods, the Landsat threshold method has the highest accuracy ( $R^{2}$ from 0.71 to 0.97 , RMSE from 0.01 to 0.14 ) at all resolutions in both study regions, particularly at finer spatial scales $(250 \times 250 \mathrm{~m}$; Table 1$)$. Of the three MODIS methods, the hierarchical training method performed with the highest accuracy $\left(R^{2}\right.$ from 0.29 to 0.97 and RMSE from 0.01 to 0.14 when validated with highresolution imagery; $\mathrm{R}^{2}$ from 0.16 to 0.71 and RMSE from 0.08 to 0.23 when validated with Landsat data) at all resolutions in both sites (Tables 1 and 2). The accuracy of the MODIS hierarchical training method was particularly high when results were aggregated at scales of $1 \times 1 \mathrm{~km}$ or greater ( $R^{2}$ up to 0.97 and RMSE as low as 0.00 when 
validated with high-resolution imagery; $\mathrm{R}^{2}$ up to 0.71 and RMSE as low as 0.09 when validated with Landsat data). These results suggest that the Landsat threshold method is the most accurate for quantifying cropping intensity, particularly at finer spatial resolutions $(250 \times 250 \mathrm{~m})$, but the MODIS hierarchical method is fairly accurate for quantifying cropping intensity when aggregated to coarser spatial resolutions $(\geq 1 \times 1 \mathrm{~km})$. We have included maps of cropped area produced by each method in the supplementary information for visual inspection (Fig. S5 and S6).

Of the two least accurate methods, the MODIS peak method performed fairly well considering adjusted $\mathrm{R}^{2}$ and Spearman's coefficients during the winter season when there is a large amount of cropped agricultural land-cover $\left(\mathrm{R}^{2}\right.$ up to 0.95 and Spearman's coefficient up to 0.98 when validated with high-resolution imagery; $\mathrm{R}^{2}$ up to 0.61 and Spearman's coefficient up to 0.87 when validated with Landsat data; Tables 1 and 2). This is particularly true at larger scales of aggregation ( $\geq 5 \times 5 \mathrm{~km}$ aggregation). Yet this method performs poorly considering RMSE measures (RMSE up to 0.41 when validated with high-resolution data; RMSE up to 0.47 when validated with Landsat data). Furthermore, this method performs very poorly during the summer season when there is less and more sparsely cropped agricultural land-cover $\left(R^{2}\right.$ as low as 0.00 when validated with high-resolution imagery and Landsat data; Tables 1 and 2). During the summer season, the MODIS TMA is more accurate $\left(\mathrm{R}^{2}\right.$ up to 0.60 and RMSE as low as 0.07 when validated with high-resolution imagery; $\mathrm{R}^{2}$ up to 0.42 and RMSE as low as 0.14 when validated with Landsat data), particularly at larger scales of aggregation $(\geq 5 \times 5 \mathrm{~km}$ aggregation; Tables 1 and 2). This is likely because the MODIS peak method over-predicts uncropped pixels when there is little cropped agriculture within a given MODIS pixel (see Fig. S1 in the Supplementary Information).

Each method performed slightly differently based on the growing season and the study region of interest. Most methods performed better during the winter than the summer season in Gujarat (Tables 1 and 2), most likely because there is little cropped area across the region during the summer season resulting in high sub-pixel heterogeneity at the MODIS scale. The analyses also performed slightly better in Gujarat than Madhya Pradesh during the winter season (Table 2). This is likely also because cropped agricultural land-cover is sparser in the Madhya Pradesh site than the Gujarat site during the winter season due to less and more heterogeneous access to irrigation.

Considering the Wilcoxon signed-rank tests on the binned quartile data (Table S6A and B), we find that the MODIS peak and the MODIS TMA method typically over-predict cropped area, particularly during the winter season when there is a greater amount of cropping in a given region. The Landsat threshold method typically under-predicts cropped area, especially at low levels of cropped area ( $<50 \%$ cropped pixels at scales of up to $5 \times 5 \mathrm{~km})$. The MODIS hierarchical method typically over-predicts cropped area at low levels of cropping $(<50 \%$ cropped area at scales of up to $10 \times 10 \mathrm{~km}$ ), particularly in Gujarat. In the Madhya Pradesh site, where cropped area is much sparser and less spatially clumped, the hierarchical method significantly under-predicts cropped area.

\subsection{Reproducibility of methods to a different region}

We found that the relative accuracy of each method did not change when used to calculate winter cropped area in a new agricultural region for each of our study regions. The overall accuracy of each of our methods, however, decreased for these new areas (Tables 3 and 4). The Landsat method still performed with the highest accuracy $\left(R^{2}\right.$ from 0.83 to 0.85 and RMSE from 0.03 to 0.14 ), especially at finer spatial resolutions of $250 \times 250 \mathrm{~m}$ (Table 3). The MODIS hierarchical technique had relatively high accuracy $\left(R^{2}\right.$ from 0.58 to 0.75 and RMSE from 0.00 to 0.14 when validated with high-resolution imagery; $R^{2}$ from 0.52 to 0.71 and RMSE from 0.10 to 0.20 when validated with Landsat data) in both Gujarat and Madhya Pradesh, particularly at aggregate scales of $1 \times 1 \mathrm{~km}$ or greater (Tables 3 and 4). Considering our two least accurate methods, the MODIS peak method outperformed the TMA during the winter season when there is a greater amount of cropped land-cover, however, the TMA outperformed the peak method during the summer season when there is little and sparsely cropped agricultural land-cover (Tables 3 and 4).

\subsection{Cropped area comparisons with agricultural census data}

Considering comparisons with agricultural census data for the districts encompassed by our study regions in Gujarat and Madhya Pradesh, we found that all four of our methods calculated a greater amount of cropped area during the winter season than measured using agricultural census data (Table S7). Given the high accuracy of our methods compared to high-resolution validation imagery, we believe that the difference between our estimates and government measures is due to underreporting of agricultural cropped area in the census data. Previous remote sensing studies have found similar results in India considering the reporting of irrigated cropped area (Dheeravath et al., 2010; Thenkabail et al., 2009).

\subsection{Criteria to identify the benefits and problems with each method}

Our qualitative analysis of each method found that though the Landsat method had the highest accuracy, particularly at finer resolutions of analysis, this method is difficult to implement across large spatial and temporal scales. In these cases, the MODIS hierarchical method may be most appropriate because it offers moderately high accuracy (particularly at aggregate scales $\geq 1 \times 1 \mathrm{~km}$ ), moderate ease of use, and is moderately easy to implement across large spatial and temporal scales (Table 5).

While the Landsat threshold method had the highest accuracy and is easy to implement since it only requires the identification of

Table 1

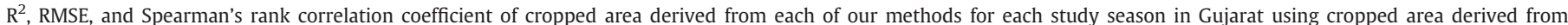

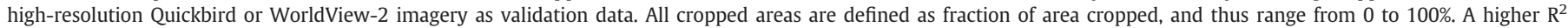

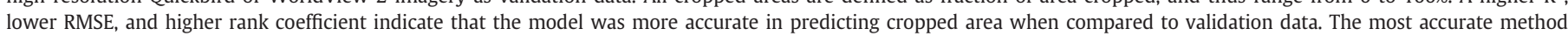
for each spatial scale of analysis and study season is highlighted in bold.

\begin{tabular}{|c|c|c|c|c|c|c|c|c|c|c|c|}
\hline \multirow[t]{2}{*}{ Region } & \multirow[t]{2}{*}{ Season } & \multirow[t]{2}{*}{ Method } & \multicolumn{3}{|c|}{$250 \times 250 \mathrm{~m}$} & \multicolumn{3}{|c|}{$1 \times 1 \mathrm{~km}$} & \multicolumn{3}{|c|}{$5 \times 5 \mathrm{~km}$} \\
\hline & & & $\mathrm{R}^{2}$ & RMSE & Rank & $\mathrm{R}^{2}$ & RMSE & Rank & $\mathrm{R}^{2}$ & RMSE & Rank \\
\hline \multirow[t]{8}{*}{ Gujarat } & \multirow[t]{4}{*}{ Winter } & Landsat & 0.85 & 0.11 & 0.92 & 0.93 & 0.08 & 0.96 & 0.97 & 0.07 & 0.98 \\
\hline & & MODIS Peak & - & - & - & 0.71 & 0.41 & 0.90 & 0.96 & 0.29 & 0.98 \\
\hline & & TMA & 0.16 & 0.44 & 0.41 & 0.46 & 0.40 & 0.68 & 0.60 & 0.43 & 0.80 \\
\hline & & Hierarchical & 0.59 & 0.19 & 0.78 & 0.86 & 0.07 & 0.93 & 0.97 & 0.01 & 0.99 \\
\hline & \multirow[t]{4}{*}{ Summer } & Landsat & 0.71 & 0.10 & 0.62 & 0.78 & 0.05 & 0.65 & 0.86 & 0.01 & 0.92 \\
\hline & & MODIS Peak & - & - & - & 0.00 & 0.05 & 0.10 & - & 0.01 & - \\
\hline & & TMA & 0.00 & 0.15 & -0.11 & 0.00 & 0.13 & -0.24 & 0.23 & 0.07 & -0.55 \\
\hline & & Hierarchical & 0.30 & 0.08 & 0.72 & 0.45 & 0.04 & 0.71 & 0.50 & 0.01 & 0.70 \\
\hline
\end{tabular}



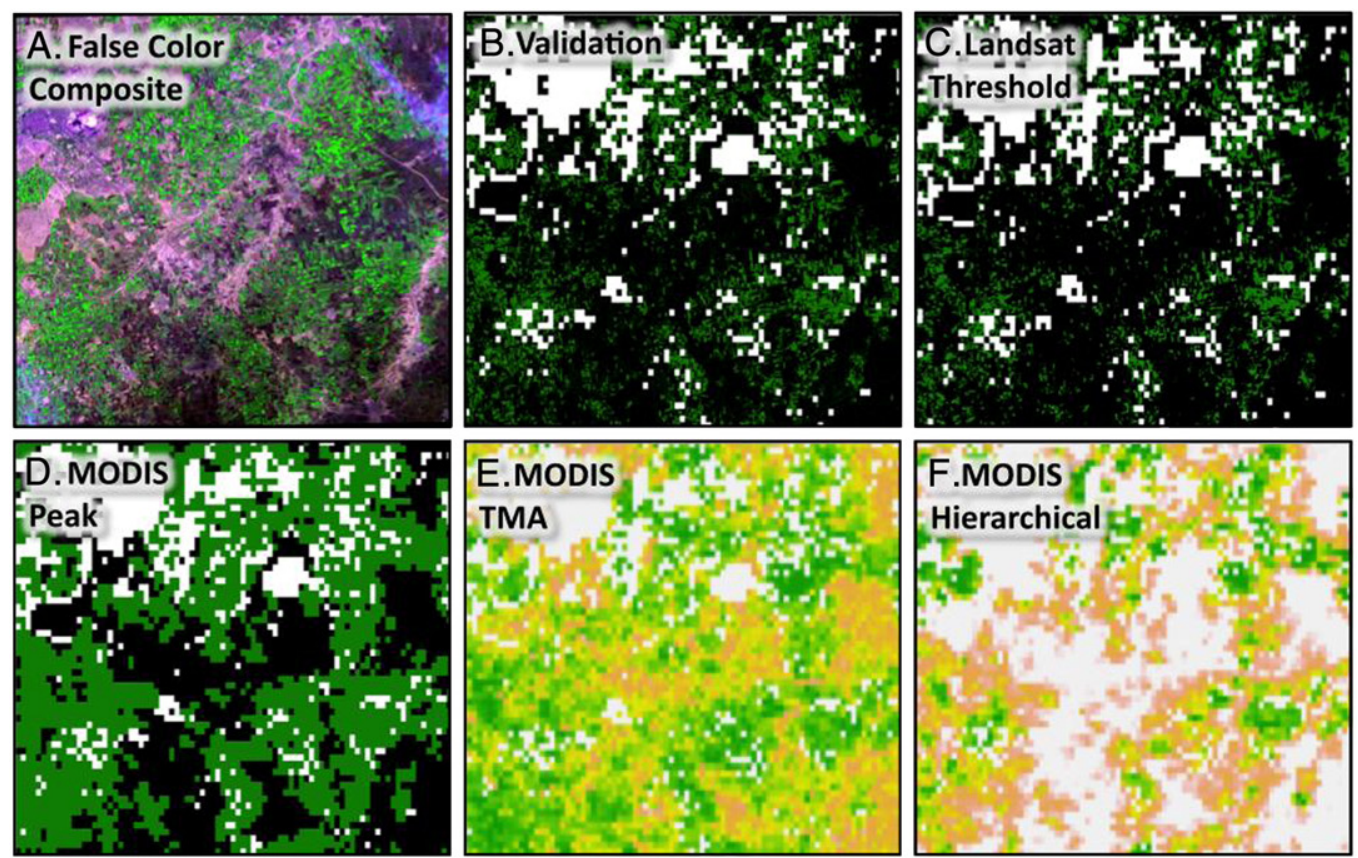

\section{Legend B - D}

\section{Legend E - F}

Cropped

Uncropped

Masked
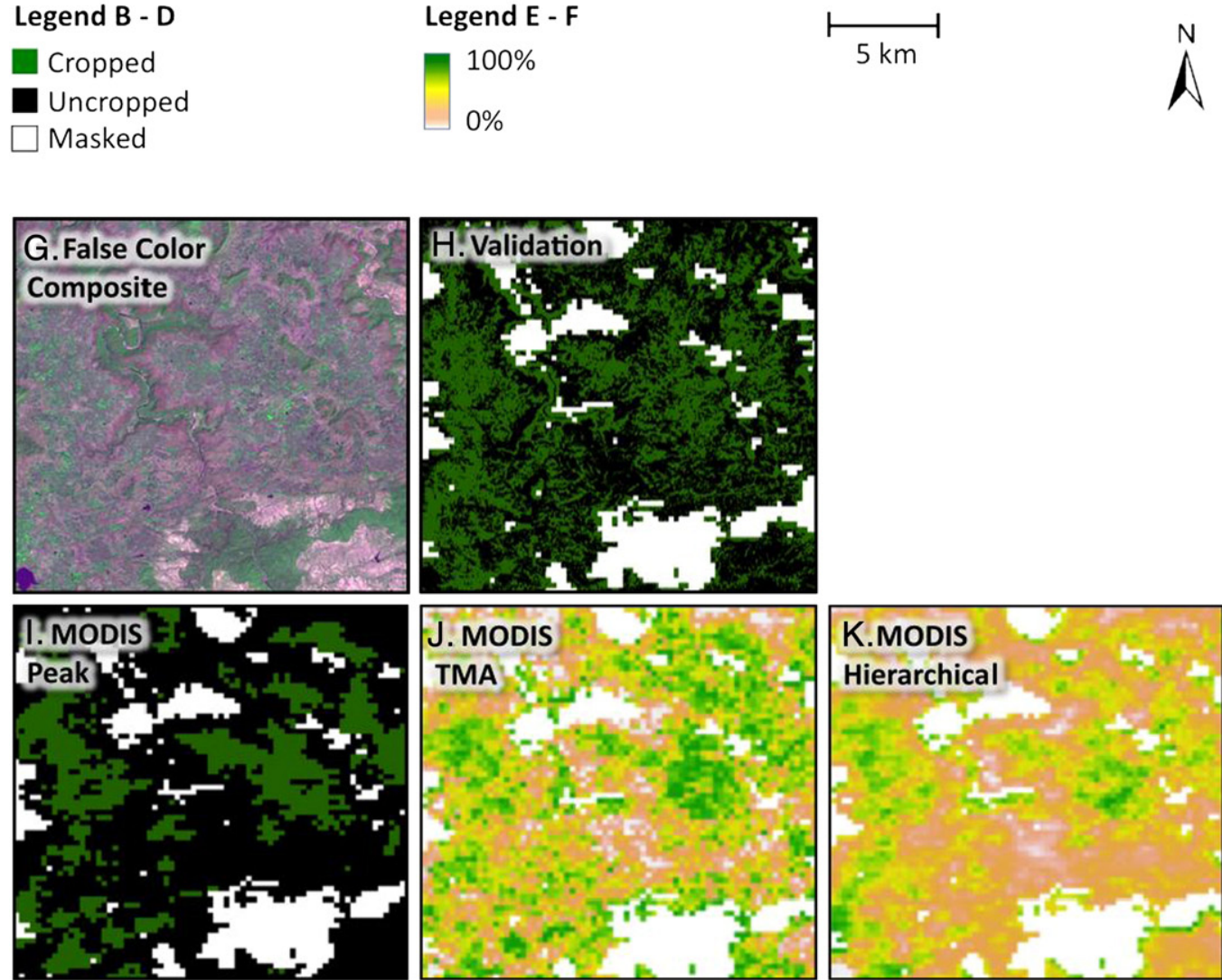

Legend $\mathbf{H}-\mathbf{I}$

Legend J - K

Cropped

Uncropped

Masked

$0 \%$
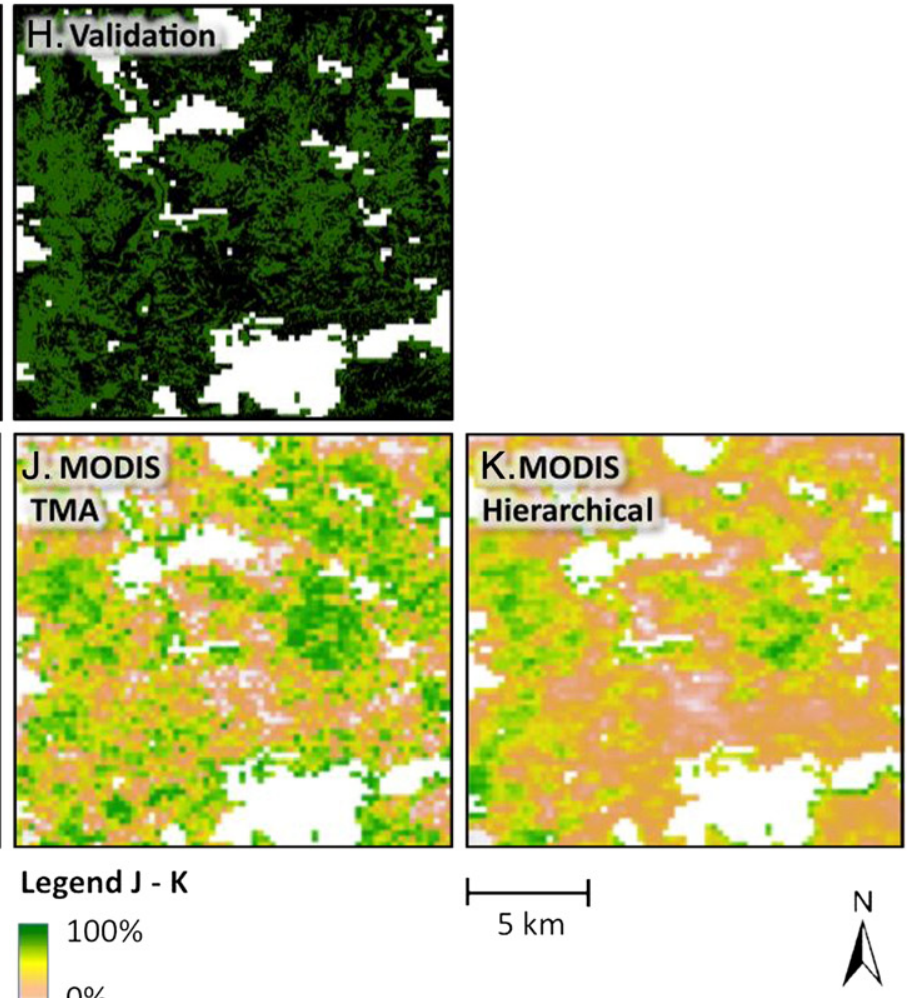

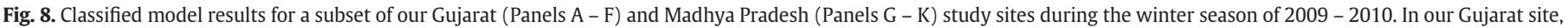

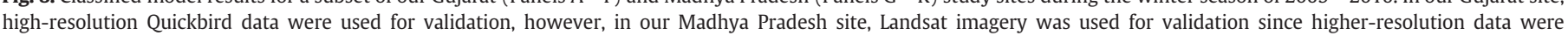

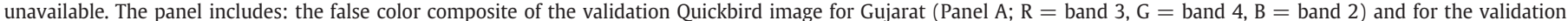

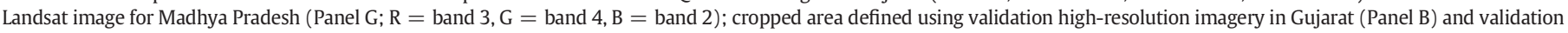

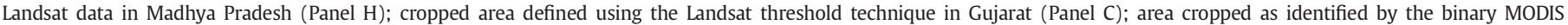

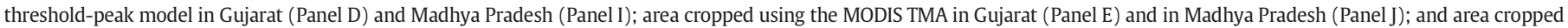

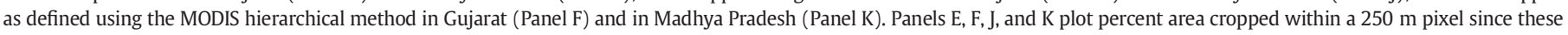
methods assess sub-pixel heterogeneity in MODIS datasets. 
Table 2

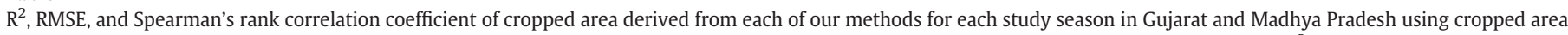

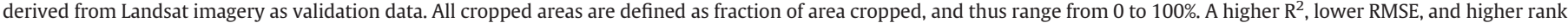

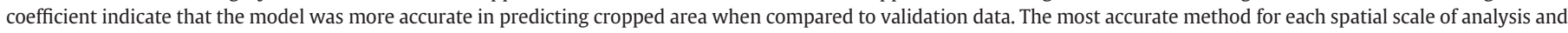
study season is highlighted in bold.

\begin{tabular}{|c|c|c|c|c|c|c|c|c|c|c|c|}
\hline \multirow[t]{2}{*}{ Region } & \multirow[t]{2}{*}{ Season } & \multirow[t]{2}{*}{ Method } & \multicolumn{3}{|c|}{$250 \times 250 \mathrm{~m}$} & \multicolumn{3}{|c|}{$1 \times 1 \mathrm{~km}$} & \multicolumn{3}{|c|}{$10 \times 10 \mathrm{~km}$} \\
\hline & & & $\mathrm{R}^{2}$ & RMSE & $\overline{\text { Rank }}$ & $\mathrm{R}^{2}$ & RMSE & $\overline{\text { Rank }}$ & $\mathrm{R}^{2}$ & RMSE & $\overline{\text { Rank }}$ \\
\hline \multirow[t]{6}{*}{ Gujarat } & \multirow[t]{3}{*}{ Winter } & MODIS Peak & - & - & - & 0.61 & 0.49 & 0.87 & 0.60 & 0.37 & 0.74 \\
\hline & & TMA & 0.15 & 0.50 & 0.43 & 0.42 & 0.47 & 0.67 & 0.38 & 0.44 & 0.59 \\
\hline & & Hierarchical & 0.53 & 0.23 & 0.76 & 0.83 & 0.10 & 0.92 & 0.58 & 0.16 & 0.70 \\
\hline & \multirow[t]{3}{*}{ Summer } & MODIS Peak & - & - & - & 0.02 & 0.09 & 0.16 & 0.00 & 0.41 & 0.29 \\
\hline & & TMA & 0.00 & 0.19 & 0.04 & 0.00 & 0.14 & 0.04 & 0.21 & 0.32 & 0.30 \\
\hline & & Hierarchical & 0.16 & 0.14 & 0.59 & 0.34 & 0.07 & 0.72 & 0.51 & 0.26 & 0.64 \\
\hline \multirow[t]{3}{*}{ Madhya Pradesh } & \multirow[t]{3}{*}{ Winter } & MODIS Peak & - & - & - & 0.26 & 0.39 & 0.43 & 0.45 & 0.28 & 0.63 \\
\hline & & TMA & 0.14 & 0.36 & 0.36 & 0.33 & 0.26 & 0.57 & 0.51 & 0.17 & 0.69 \\
\hline & & Hierarchical & 0.51 & 0.23 & 0.73 & 0.66 & 0.15 & 0.83 & 0.71 & 0.09 & 0.87 \\
\hline
\end{tabular}

a threshold, it performs poorly with respect to data availability and the ability to use the method over large spatial and temporal scales. This is because Landsat data may have poor coverage, particularly in the tropics where there is high cloud cover, and because it is cumbersome to calibrate and mosaic multiple Landsat images across large scales (e.g. Canty \& Nielsen, 2008).

The MODIS hierarchical training method performs moderately with respect to all four of our criteria. Accuracy is relatively high, particularly at larger scales of aggregation ( $\geq 1 \times 1 \mathrm{~km})$. The method is moderately easy to use given that calibration analyses can be done using simple linear regressions. Considering the criteria of data availability and the ability to use the method over large scales, while the hierarchical training method requires the use of some high-resolution (i.e. Quickbird, Worldview-2, or Google Earth imagery) and Landsat imagery to train the MODIS model, once the model is trained it is feasible to use only MODIS data to assess cropping intensity across larger regions. Based on our reproducibility results (Section 3.2), this method can likely be used to assess cropping intensity accurately within the same agro-ecological zone where crop type, soil type, and topography remain similar, however, it is unclear how much further our analyses can extend without having to perform new region-specific calibration.

The MODIS TMA method performs well considering the criteria of data availability and the ability to use the method over large spatial and temporal scales, however, the analysis performs poorly considering accuracy and ease of use. The main benefit of the TMA is that only MODIS data are required to quantify cropping intensity. The accuracy of this method, however, is much lower compared to the Landsat threshold and MODIS hierarchical models, our two most accurate methods (Tables 1 and 2).

Finally, the MODIS peak method does moderately well considering ease of use over large spatial and temporal scales and data availability. Like the hierarchical training technique, some high-resolution and Landsat imagery are required to train the model, but once the model is trained only MODIS data can be used to conduct the method over larger regions. Our reproducibility results suggest that this method can be used without re-calibration within the same agro-ecological zone where crop type, soil type, and topography remain constant, however, it is unclear how much further analyses can extend without re-calibration. Considering accuracy, this method does well in regions and seasons when there is a large amount of cropped agricultural land-cover, however, it performs very poorly when there is little and sparsely cropped agricultural landcover given that the method over-predicts uncropped pixels.

\section{Discussion}

Our study assesses multiple methods to map cropping intensity of smallholder agriculture where the spatial resolution of one farm is typically smaller than the spatial resolution of readily available satellite imagery. We assessed how each of our four methods performed based on several criteria: the accuracy of the method, availability of required data, ease of use, and applicability of the method over large spatial and temporal scales (Table 5). There are several broad conclusions that can be drawn from our results. First, we find that the most appropriate method depends on the criteria of interest. The most accurate method to map cropping intensity across our study seasons and regions is the Landsat threshold method (Table 1). Yet given the difficulty of using this method across large spatial and temporal scales, the MODIS hierarchical training method that calibrates EVI values to validation imagery may be a more appropriate method for large-scale analyses. Considering data availability, the only method that does not require high-resolution or Landsat imagery for model training is the MODIS TMA. Thus, even though this method has relatively low accuracy, it may be the most appropriate to use in cases where there is no access to higher resolution datasets. Second, we find that the accuracy of our methods generally increased when the results were aggregated to coarser spatial resolutions (Tables 1 and 2). Finally, the accuracy of each method varied based on the growing season and region in question (Tables 1 and 2). Our models, particularly the MODIS-derived methods, are less accurate in regions and seasons with sparsely cropped agricultural land-cover. This is likely due to high sub-pixel heterogeneity at the MODIS scale, which results in over-prediction of uncropped agriculture.

The Landsat threshold method was uniformly the most accurate across the study regions and growing seasons considered in our analyses, particularly at the level of $250 \times 250 \mathrm{~m}$. This is intuitive given that the size of a Landsat pixel ( $30 \mathrm{~m}$ resolution) most closely matches the spatial resolution of individual smallholder agricultural fields, resulting in little sub-pixel heterogeneity. These results correspond to previous studies that have found that Landsat most accurately maps irrigated area in India compared to coarser resolution sensors (Velpuri et al., 2009). Despite high accuracy, the Landsat method is more difficult to use regarding data availability and the ability to apply this method over large spatial and temporal scales. Landsat images are often unavailable during wet growing seasons or in tropical regions when there is high cloud cover, as evidenced by missing Landsat scenes for the monsoon season in both regions. Data availability issues are exacerbated when using Landsat 7 ETM + due to problems with the Scan Line Corrector malfunction in 2003, which results in stripes of missing values across all but the center of the image. Furthermore, Landsat is difficult to use over large spatial and temporal scales since it can be cumbersome to mosaic and calibrate images through space and time. Given these concerns, the Landsat threshold method is most appropriate for assessing cropped area over small spatial and temporal scales in regions with little to no cloud cover.

For quantifying cropping intensity over large spatial and temporal scales, the hierarchical training technique that calibrates MODIS EVI values to higher-resolution ground-truth imagery may be the most appropriate method. While the accuracy of this technique is typically lower than that of the Landsat threshold method, it was consistently 
Table 3

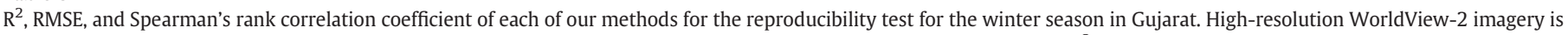

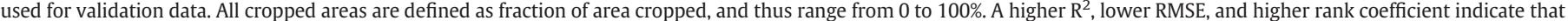
the model was more accurate in predicting cropped area when compared to validation data. The most accurate method for each spatial scale of analysis is highlighted in bold.

\begin{tabular}{|c|c|c|c|c|c|c|c|c|c|c|c|}
\hline \multirow[t]{2}{*}{ Region } & \multirow[t]{2}{*}{ Season } & \multirow[t]{2}{*}{ Method } & \multicolumn{3}{|c|}{$250 \times 250 \mathrm{~m}$} & \multicolumn{3}{|c|}{$1 \times 1 \mathrm{~km}$} & \multicolumn{3}{|c|}{$5 \times 5 \mathrm{~km}$} \\
\hline & & & $\overline{\mathrm{R}^{2}}$ & RMSE & $\overline{\text { Rank }}$ & $\overline{\mathrm{R}^{2}}$ & RMSE & $\overline{\text { Rank }}$ & $\overline{\mathrm{R}^{2}}$ & RMSE & $\overline{\text { Rank }}$ \\
\hline \multirow[t]{4}{*}{ Gujarat } & Winter & Landsat & 0.85 & 0.14 & 0.86 & 0.83 & 0.07 & 0.91 & 0.94 & 0.03 & 0.99 \\
\hline & & MODIS Peak & - & - & - & 0.50 & 0.18 & 0.64 & 0.87 & 0.09 & 0.98 \\
\hline & & TMA & 0.00 & 0.39 & 0.04 & 0.00 & 0.36 & 0.04 & 0.57 & 0.38 & 0.78 \\
\hline & & Hierarchical & 0.59 & 0.14 & 0.70 & 0.75 & 0.05 & 0.85 & 0.98 & 0.00 & 0.99 \\
\hline
\end{tabular}

highest across our three MODIS methods. Regarding ease of use, this method is moderately difficult because it requires a separate analysis to calibrate EVI values. With respect to data availability and the ability to use this method over large spatial and temporal scales, though this method uses high-resolution imagery and Landsat data to train the calibration algorithm, these data are only required over a small spatial scale. Once the hierarchical model is calibrated, it can then be used to calculate cropped area using only MODIS imagery. Our reproducibility tests suggest that the same calibrated model can be used to accurately quantify cropping intensity for agricultural areas within the same agro-ecological zone where crop type, soil type, climatic patterns, and topography are similar, however, it is likely that the model should be re-calibrated in new regions where these factors vary significantly. This is evidenced by the fact that we had to calculate separate calibration algorithms for our Gujarat and Madhya Pradesh sites. Future studies should assess the spatial extent over which these models can be used without re-calibration.

All of our models require at least one high-resolution or Landsat scene for training and calibration, except for the MODIS TMA. Endmember phenologies are selected using an EOF analysis of only MODIS data, and these phenologies are then used in a linear mixture analysis to quantify the percent of each pixel that is single, double, and triple cropped. The accuracy of this method, however, is variable, even at coarser spatial aggregations of $10 \times 10 \mathrm{~km}\left(\mathrm{R}^{2}\right.$ from 0.23 to 0.60 when validated with high-resolution imagery and $R^{2}$ from 0.20 to 0.38 when validated with Landsat data). Furthermore, this model did not perform very well in our reproducibility tests $\left(\mathrm{R}^{2}<.4\right.$ at $10 \times 10 \mathrm{~km}$ aggregation). This may be because the EVI green-up and green-down dates of single, double, and triple cropping differ between the region used to select our TMA end-members and the region used for our reproducibility test. Despite relatively low accuracy, the TMA may be appropriate if only MODIS data are available for quantifying cropping intensity over the region of interest.

The MODIS peak method had high accuracy in regions and seasons with a large amount of cropped agricultural land-cover, such as the winter season in Gujarat ( $\mathrm{R}^{2}$ up to 0.95 at $10 \times 10 \mathrm{~km}$ aggregation). Yet the method had the lowest accuracy of all four of our methods considering RMSE (RMSE up to 0.47 ) and when used to quantify cropped area in regions and seasons with little, sparsely cropped agriculture $\left(\mathrm{R}^{2}\right.$ up to 0.02 ). This is likely because the MODIS peak method assigns a binary value to each MODIS pixel (i.e. either cropped or uncropped) and, thus, over-predicts uncropped pixels when cropped land-cover is sparse (see Fig. S1 in the Supplementary Information). These results are of particular interest since the peak method has been the most widely used method in the literature to quantify cropping intensity using MODIS data (e.g. Biradar \& Xiao, 2011). It is important to note that our MODIS peak method slightly differed from those used to calculate cropping intensity in previous studies because we additionally applied a threshold constraint to define cropped agriculture, which improved accuracy in our study regions.

All analyses had improved accuracy at coarser spatial aggregations. For example $\mathrm{R}^{2}$ values were typically low the $250 \times 250 \mathrm{~m}$ scale $\left(R^{2}<.6\right)$ but increased at scales of $1 \times 1 \mathrm{~km}$ and greater $\left(R^{2}\right.$ as high as 0.95 ). This suggests that it is best to quantify cropping intensity at as large of spatial aggregation scales as possible (e.g. $\geq 10 \times 10 \mathrm{~km}$ ), where over-prediction and under-prediction of cropped area at the pixel level evens out (Potgieter et al., 2007). In cases where smaller scale analyses must be conducted, our Landsat method does reasonably well at scales greater than or equal to $250 \times 250 \mathrm{~m}$, and the MODIS hierarchical training method does well at scales greater than or equal to $1 \times 1 \mathrm{~km}$.

It is important to consider how well our models might perform in different regions. Based on our reproducibility tests, our methods achieve the same relative accuracy when we apply our derived algorithms to another area within the same agro-ecological zone, where crop type, soil type, topography, and climate patterns remain constant. This suggests that the scaling relationships and cropping algorithms that we derive in one area may be applicable to a wider region than simply the scene used to train our models. It is important to note, however, that it is unclear how reproducible our algorithms are across very large regions (e.g. multiple Landsat scenes). The fact that we had to calculate different threshold values and calibration relationships for each of our methods in our two study sites (i.e. Gujarat and Madhya Pradesh) suggests that we need to independently derive our models for regions that vary based on factors such as climatology, agro-ecological zone, and topography. It is also important to consider

Table 4

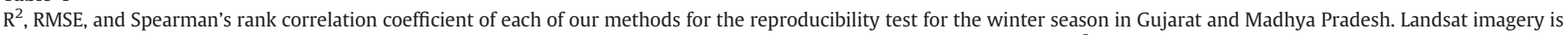

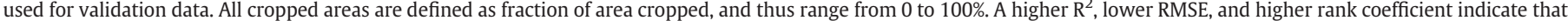

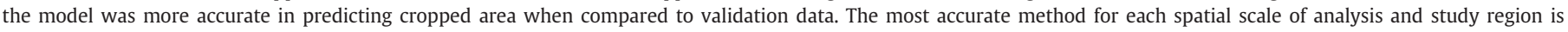
highlighted in bold.

\begin{tabular}{|c|c|c|c|c|c|c|c|c|c|c|c|}
\hline \multirow[t]{2}{*}{ Region } & \multirow[t]{2}{*}{ Season } & \multirow[t]{2}{*}{ Method } & \multicolumn{3}{|c|}{$250 \times 250 \mathrm{~m}$} & \multicolumn{3}{|c|}{$1 \times 1 \mathrm{~km}$} & \multicolumn{3}{|c|}{$10 \times 10 \mathrm{~km}$} \\
\hline & & & $\mathrm{R}^{2}$ & RMSE & Rank & $\mathrm{R}^{2}$ & RMSE & Rank & $\mathrm{R}^{2}$ & RMSE & Rank \\
\hline \multirow[t]{3}{*}{ Gujarat } & \multirow[t]{6}{*}{ Winter } & MODIS Peak & - & - & - & 0.50 & 0.17 & 0.68 & 0.42 & 0.22 & 0.71 \\
\hline & & TMA & 0.00 & 0.43 & 0.07 & 0.00 & 0.36 & 0.10 & 0.37 & 0.17 & 0.66 \\
\hline & & Hierarchical & 0.56 & 0.20 & 0.67 & 0.70 & 0.08 & 0.81 & 0.77 & 0.11 & 0.89 \\
\hline \multirow[t]{3}{*}{ Madhya Pradesh } & & MODIS Peak & - & - & - & 0.19 & 0.35 & 0.45 & 0.14 & 0.31 & 0.44 \\
\hline & & TMA & 0.35 & 0.27 & 0.53 & 0.34 & 0.21 & 0.50 & 0.43 & 0.14 & 0.60 \\
\hline & & Hierarchical & 0.65 & 0.20 & 0.77 & 0.76 & 0.14 & 0.79 & 0.70 & 0.10 & 0.84 \\
\hline
\end{tabular}


Table 5

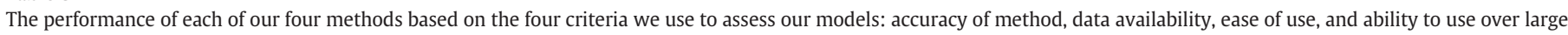

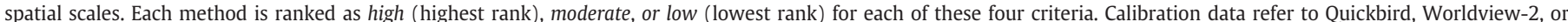

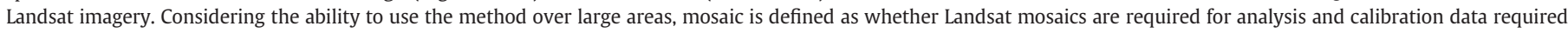
suggests that some high-resolution or Landsat data must be available to calibrate the model.

\begin{tabular}{|c|c|c|c|c|c|c|c|c|}
\hline \multirow[t]{2}{*}{ Method } & \multicolumn{2}{|l|}{ Accuracy } & \multicolumn{2}{|l|}{ Data availability } & \multicolumn{2}{|l|}{ Ease of use } & \multicolumn{2}{|l|}{ Ability to use over large areas } \\
\hline & $\mathrm{R}^{2}$ range & Rank & Data required & Rank & Technique & Rank & Mosaic/Calibration data required & Rank \\
\hline Landsat & $0.71-0.97$ & High & Landsat & Low & Threshold & High & Yes/Yes & Low \\
\hline MODIS Peak & $0.00-0.95$ & Low & Calibration data, MODIS & Moderate & Count peaks, Threshold & Moderate & No/Yes & Moderate \\
\hline TMA & $0.01-0.60$ & Low & MODIS & High & Temporal mixture analysis & Low & No/No & High \\
\hline Hierarchical & $0.16-0.97$ & Moderate & Calibration data, MODIS & Moderate & Calibrate EVI value & Moderate & No/Yes & Moderate \\
\hline
\end{tabular}

how our models might perform in regions of smallholder farming outside of India where agriculture land-cover may be more sparsely cropped and there is high heterogeneity in land-cover classes. All models performed best during the winter season, when there was a large amount of cropped agriculture and there was little confusion between cropped agriculture and other land-cover classes (since scrubland remains bare in non-monsoon seasons). Our models performed the least well during the summer season, when cropped fields are sparse and disaggregated due to little and heterogeneous irrigation access. This made it more difficult to accurately quantify cropped area using Landsat and MODIS sensors due to the higher chance of sub-pixel heterogeneity. The relative performance of our models, however, remained constant. This suggests that increased heterogeneity in crop cover may reduce the accuracy of our models, but the relative accuracy and decision for which model to use will likely remain the same. In addition, in regions that have high spatial heterogeneity in land-cover classes (i.e. agriculture mixed with bushes and forests), we argue that higher resolution imagery (i.e. Quickbird or Landsat) should be used to create the non-agricultural mask that is applied before analysis. This will improve accuracy of all models since it will apply our four crop detection methods to mostly agricultural pixels.

Our analyses focused on using readily available Landsat and MODIS data, however, there are other remote sensing products available for our study region that may be used to classify cropped area. For example, many studies use microwave RADAR data to detect cropping patterns; this is because RADAR uses relatively long wavelengths that can easily pass through cloud cover as well as atmospheric particulate matter, resulting in high quality data even during periods of high cloud cover. Current commercial global products are available at relatively fine spatial (approximately $10 \mathrm{~m} \times 10 \mathrm{~m}$; e.g. ALOS-PALSAR) and temporal resolutions (approximately every 45 days for some regions; e.g. ALOS-PALSAR). Previous studies have found that RADAR products, both airplane and satellite derived, can discriminate crop type by up to $60 \%$ to $96 \%$ (Bouvet et al., 2009). While RADAR appears to be a relevant step forward, there are several issues that make its use more difficult than readily available imagery like Landsat and MODIS. First, the temporal coverage of RADAR products may not be optimal depending on the location of the study, particularly if image dates do not align with crop calendars of a given region. Second, a significant amount of processing may be required to accurately geo-reference and co-register multiple images (Chakraborty et al., 1999). Finally, the cost of RADAR products is typically high (i.e. several hundred dollars per image) making its use over large areas and timescales prohibitive. In addition, for India specifically, several remote sensing products are available from the Indian Space Research Organization. These include RADAR products as well as multi-spectral passive satellites. While these data have been used to accurately classify cropped area in India with up to 95\% accuracy (e.g. Panigrahy \& Sharma, 1997; Sahoo et al., 2012), these products are not readily available for use and are difficult to obtain if not affiliated with an Indian government or educational institution. We therefore did not consider these data in our analyses.

\section{Conclusion}

Though quantifying cropping intensity is an important step in assessing food security, current remote sensing techniques may not accurately map the cropping intensity of smallholder farms where the size of one field (typically $\leq 2$ ha) is typically smaller than the spatial resolution of readily available satellite data like Landsat and MODIS. To identify the best ways to quantify cropping intensity of smallholder farms, our study assessed how well four classification methods from the literature performed based on multiple criteria: the accuracy of the method, availability of required data, ease of use, and applicability of the method over large spatial and temporal scales (Table 5 ). The four methods considered in our study are a Landsat threshold technique (Section 2.3.1), a method that identifies peaks in MODIS time series (Section 2.3.2), a TMA using MODIS data (Section 2.3.3), and a hierarchical technique that trains MODIS data using higher resolution imagery (Section 2.3.4). In conclusion, our results suggest that it is possible to accurately map cropping intensity of smallholder agriculture using Landsat and MODIS. The method that is most appropriate for a given area depends on the goals of the study, the scale of analysis, and the characteristics of the agricultural system in question. Our Landsat threshold method is most appropriate to quantify cropping intensity of individual farm plots over small spatial and temporal scales, particularly in arid to semi-arid regions where cloud contamination does not pose a problem for data availability. For studies that analyze cropping intensity over large spatial and temporal scales, we suggest that the MODIS hierarchical training method may be the most appropriate analysis. This method had moderately high accuracy, especially at spatial aggregations greater than or equal to $1 \times 1 \mathrm{~km}$, had moderate ease of use, and was moderately easy to implement over large spatial scales, at least within the same agro-ecological zone where calibration relationships remained constant. In cases where no Landsat or high-resolution data are available, we suggest that researchers use the MODIS TMA method. Yet given the low accuracy of this method, particularly at smaller scales, we suggest that this method only be used to map cropping intensity at aggregate scales of at least $10 \times 10 \mathrm{~km}$.

\section{Acknowledgements}

We thank Jaime Nickelson and colleagues at the NASA Cad4 Database for providing the necessary high-resolution Quickbird and WorldView-2 imagery for our analyses. We also thank the DeFries lab group for constructive comments on this work. We would like to thank three anonymous reviewers for their helpful and constructive feedback on earlier versions of this manuscript. Funding was provided by NASA LCLUC grant NNX11AH98G and an NSF GRF awarded to M. Jain.

\section{Appendix A. Supplementary data}

Supplementary data to this article can be found online at http:// dx.doi.org/10.1016/j.rse.2013.02.029. 


\section{References}

Benedetti, R., \& Rossini, P. (1993). On the use of NDVI profiles as a tool for agricultural statistics: The case study of wheat yield estimate and forecast in Emilia Romagna. Remote Sensing of Environment, 45, 311-326.

Biradar, C. M., \& Xiao, X. (2011). Quantifying the area and spatial distribution of doubleand triple- cropping croplands in India with multi-temporal MODIS imagery in 2005 International Journal of Remote Sensing, 32(2), 367-386.

Bouvet, A., Le Toan, T., \& Lam-Dao, Nguyen (2009). Monitoring of the rice cropping system in the Mekong Delta using ENVISAT/ASAR dual polarization data. IEEE Transactions on Geoscience and Remote Sensing, 47(2), 517-526.

Braswell, B. H., Hagen, S. C., Frolking, S. E., \& Salas, W. A. (2003). A multivariable approach for mapping sub-pixel land cover distributions using MISR and MODIS: Application in the Brazilian Amazon region. Remote Sensing of Environment, 87(2-3), 243-256.

Breiman, L. (2001). Random forests. Machine Learning, 45(1), 5-32.

Brisco, B., Brown, R. J., Hirose, T., McNairn, H., \& Staenz, K. (1998). Precision agriculture and the role of remote sensing: A review. Canadian Journal of Remote Sensing, 24, 315-327.

Butler, L. B. (1999). Comparing effects of aggregation methods on statistical and spatial properties of simulated spatial data. Photogrammetric Engineering and Remote Sensing, 65(1), 73-84.

Canty, M. J., \& Nielsen, A. A. (2008). Automatic radiometric normalization of multitemporal satellite imagery with the iteratively re-weighted MAD transformation. Remote Sensing of Environment, 112(3), 1025-1036.

Chakraborty, M., Parihar, J. S., \& Panigrahy, S. (1999). Operational use of SAR images for crop surveillance - Issues regarding congruency accuracy. Presented at the CEOS SAR Workshop, Toulouse, France (pp. 1-7).

Collins, W. (1978). Remote sensing of crop type and maturity. Photogrammetric Engineering and Remote Sensing, 44, 43-55.

Dai, X., \& Khorram, S. (1998). A hierarchical methodology framework for multisource data fusion in vegetation classification. International Journal of Remote Sensing 19(18), 3697-3701.

DeFries, R. S., \& Chan, J. C. -W. (2000). Multiple criteria for evaluating machine learning algorithms for land cover classification from satellite data. Remote Sensing of Environment 74, 503-515.

Dheeravath, V., Thenkabail, P. S., Chandrakantha, G., Noojipady, P., Reddy, G. P., Biradar C. M., et al. (2010). Irrigated areas of India derived using MODIS $500 \mathrm{~m}$ time series for the years 2001-2003. ISPRS Journal of Photogrammetry and Remote Sensing, 65(1), 42-59.

Dubash, N. K. (2002). Tubewell capitalism: Groundwater development and agrarian change in Gujarat. Oxford University Press.

Fan, S., Hazell, P., \& Haque, T. (2000). Targeting public investments by agro-ecological zone to achieve growth and poverty alleviation goals in rural India. Food Policy, 25, 411-428.

Fang, H., Wu, B., Liu, H., \& Huang, X. (1998). Using NOAA AVHRR and Landsat TM to estimate rice area year-by-year. International Journal of Remote Sensing, 19(3), 521-525.

Foster, A. D., \& Rosenzweig, M. R. (2004). Agricultural productivity growth, rural economic diversity, and economic reforms: India, 1970-2000. Economic Development and Cultural Change, 52(3), 509-542.

Fuller, D. O. (1998). Trends in NDVI time series and their relation to rangeland and crop production in Senegal, 1987-1993. International Journal of Remote Sensing, 19(10), 2013-2018.

Gadgil, S. (2003). The Indian monsoon and its variability. Annual Review of Earth and Planetary Sciences, 31, 429-467.

Gajbhiye, K. S., \& Mandal, C. (2000). Agro-ecological zones, their soil resource and cropping systems. National Bureau of Soil Survey and Land Use Planning.

Galford, G. L., Mustard, J. F., Melillo, J., Gendrin, A., Cerri, C. C., \& Cerri, C. E. P. (2008), Wavelet analysis of MODIS time series to detect expansion and intensification of row-crop agriculture in Brazil. Remote Sensing of Environment, 112, 576-587.

Huete, A., Didan, K., Miura, T., Rodriguez, E. P., Gao, X., \& Ferreira, L. G. (2002). Overview of the radiometric and biophysical performance of the MODIS vegetation indices. Remote Sensing of Environment, 83, 195-213.

Huete, A. R., Liu, H. Q., Batchily, K., \& van Leeuwen, W. (1997). A comparison of vegetation indices over a global set of TM images for EOS-MODIS. Remote Sensing of Environment, $59,440-451$.

Indiastat (2012). State-wise Area Under Crops. http://www.indiastat.com

IRI/LDEO Climate Data Library (2012). Columbia University. http://iridl.ldeo.columbia.edu

Leichenko, R. M., \& O'Brien, K. L. (2002). The dynamics of rural vulnerability to globa change: The case of Southern Africa. Mitigation and Adaptation Strategies for Globa Change, 7, 1-18

Lenney, M. P., Woodcock, C. E., Collins, J. B., \& Hamdi, H. (1996). The status of agricultural lands in Egypt: The use of multitemporal NDVI features derived from Landsat TM. Remote Sensing of Environment, 56, 8-20.

Lobell, D. B., \& Asner, G. P. (2004). Cropland distributions from temporal unmixing of MODIS data. Remote Sensing of Environment, 93, 412-422.

Lobell, D. B., Burke, M. B., Tebaldi, C., Mastrandrea, M. D., Falcon, W. P., \& Naylor, R. L. (2008). Prioritizing climate change adaptation needs for food security in 2030. Science, 319(5863), 607-610.

Lobell, D. B., Sibley, A., \& Ortiz-Monasterio, J. I. (2012). Extreme heat effects on wheat senescence in India. Nature Climate Change, 2, 186-189.

Macedo, M. N., DeFries, R. S., Morton, D. C., Stickler, C. M., Galford, G. L., \& Shimabukuro, Y. E. (2012). Decoupling of deforestation and soy production in the southern Amazon during the late 2000s. Proceedings of the National Academy of Sciences of the United States of America, 109(4), 1341-1346.
Mahtab, F. U., \& Karim, Z. (1992). Population and agricultural land use: Towards a sustainable food production system in Bangladesh. Ambio, 21(1), 50-55.

Martínez-Casasnovas, J. A., Martín-Montero, A., \& Auxiliadora Casterad, M. (2005). Mapping multi-year cropping patterns in small irrigation districts from time-series analysis of Landsat TM images. European Journal of Agronomy, 23, 159-169.

Maxwell, S. K., Nuckols, J. R., Ward, M. H., \& Hoffer, R. M. (2004). An automated approach to mapping corn from Landsat imagery. Computers and Electronics in Agriculture, 43, 43-54.

Mayer, D. G., \& Butler, D. G. (1993). Statistical validation. Ecological Modelling, 68, $21-32$.

Ministry of Agriculture (2010). Crop calendar of major crops. Government of India.

Morton, J. F. (2007). The impact of climate change on smallholder and subsistence agriculture. Proceedings of the National Academy of Sciences, 104(50), 19680-19685.

Morton, D. C., Defries, R. S., Shimabukuro, Y. E., Anderson, L. O., Arai, E., Del Bon Espirito-Santo, F., et al. (2006). Cropland expansion changes deforestation dynamics in the southern Brazilian Amazon. Proceedings of the National Academy of Sciences of the United States of America, 103(39), 14637-14641.

Narain, D., \& Roy, S. (1980). Impact of irrigation and labor availability on multiple cropping: A case study of India, 20. (pp. 1-41). International Food Policy Research Institute.

O'Brien, K., Leichenko, R., Kelkar, U., Venema, H., Aandahl, G., Tompkins, H., et al. (2004). Mapping vulnerability to multiple stressors: Climate change and globalization in India. Global Environmental Change-Human and Policy Dimensions, 14, 303-313.

Odenweller, J. B., \& Johnson, K. I. (1984). Crop identification using Landsat temporal-spectral profiles. Remote Sensing of Environment, 14, 39-54.

Ozdogan, M., Woodcock, C., Salvucci, G., \& Demir, H. (2006). Changes in summer irrigated crop area and water use in Southeastern Turkey from 1993 to 2002: Implications for current and future water resources. Water Resources Management, 20(3), 467-488.

Panigrahy, S., \& Sharma, S. A. (1997). Mapping of crop rotation using multidate Indian Remote Sensing Satellite digital data. ISPRS Journal of Photogrammetry and Remote Sensing, 52, 85-91.

Potgieter, A. B., Apan, A., Dunn, P., \& Hammer, G. (2007). Estimating crop area using seasonal time series of Enhanced Vegetation Index from MODIS satellite imagery. Australian Journal of Agricultural Research, 58(4), 316-325.

Pretty, J. N., Morison, J. I. L., \& Hine, R. E. (2003). Reducing food poverty by increasing agricultural sustainability in developing countries. Agriculture, Ecosystems and Environment, 95, 217-234.

Quarmby, N. A., Townshend, J. R. G., Settle, J. J., White, K. H., Milnes, M., Hindle, T. L., et al. (1992). Linear mixing modelling applied to AVHRR data for crop area estimation. International Journal of Remote Sensing, 13(3), 415-425.

Richardson, A. J., \& Weigand, C. L. (1977). Distinguishing vegetation from soil background information. Photogrammetric Engineering and Remote Sensing, 43, 1541-1552.

Sahoo, P. M., Rai, A., Ahmad, T., Singh, R., \& Handique, B. K. (2012). Estimation of acreage under paddy crop in Jaintia Hills District of Meghalaya using remote sensing and GIS. International Journal of Agricultural and Statistical Sciences, 8(1), 193-202.

Sakamoto, T., Phung, C. V., Kotera, A., Nguyen, K. D., \& Yokozawa, M. (2009). Analysis of rapid expansion of inland aquaculture and triple rice-cropping areas in a coastal area of the Vietnamese Mekong Delta using MODIS time-series imagery. Landscape and Urban Planning, 92, 34-46.

Sakamoto, T., Wardlow, B. D., Gitelson, A. A., Verma, S. B., Suyker, A. E., \& Arkebauer, T. J. (2010). A two-step filtering approach for detecting maize and soybean phenology with time-series MODIS data. Remote Sensing of Environment 114(10), 2146-2159.

Sakamoto, T., Yokozawa, M., Toritani, H., Shibayama, M., Ishitsuka, N., \& Ohno, H. (2005). A crop phenology detection method using time-series MODIS data. Remote Sensing of Environment, 96, 366-375.

Sims, D. A., Rahman, A. F., Cordova, V. D., El-Masri, B. Z., Baldocchi, D. D., Flanagan, L. B., et al. (2006). On the use of MODIS EVI to assess gross primary productivity of North American ecosystems. Journal of Geophysical Research, 111(G04015).

Singh, R. B., Kumar, P., \& Woodhead, T. (2002). Smallholder farmers in India: Food security and agricultural policy. Bangkok, Thailand: FAO Regional Office for Asia and the Pacific.

Small, C. (2012). Spatiotemporal dimensionality and time-space characterization of multitemporal imagery. Remote Sensing of Environment, 124, 793-809.

Tao, F., Yokozawa, M., Xu, Y., Hayashi, Y., \& Zhang, Z. (2006). Climate changes and trends in phenology and yields of field crops in China, 1981-2000. Agricultural and Forest Meteorology, 138, 82-92.

Thenkabail, P. S., Biradar, C. M., Noojipady, P., Dheeravath, V., Li, Y., Velpuri, M., et al. (2009). Global irrigated area map (GIAM), derived from remote sensing, for the end of the last millennium. International Journal of Remote Sensing, 30(14), 3679-3733.

Thenkabail, P. S., Knox, J. W., Ozdogan, M., Gumma, M. K., Congalton, R. G., Wu, Z., et al. (2012). Assessing future risks to agricultural productivity, water resources and food security: how can remote sensing help? Photogrammetric Engineering and Remote Sensing, August 2012 Special Issue on Global Croplands: Highlight Article, 78(8). (pp. 773-782)

Velpuri, N. M., Thenkabail, P. S., Gumma, M. K., Biradar, C., Dheeravath, V., Noojipady, P., et al. (2009). Influence of resolution in irrigated area mapping and area estimation. Photogrammetric Engineering and Remote Sensing, 75(12), 1383-1395.

Wardlow, B. D., Egbert, S. L., \& Kastens, J. H. (2007). Analysis of time-series MODIS $250 \mathrm{~m}$ vegetation index data for crop classification in the U.S. Central Great Plains. Remote Sensing of Environment, 108(3), 290-310.

Xiao, X., Boles, S., Liu, J., Zhuang, D., Frolking, S., Li, C., et al. (2005). Mapping paddy rice agriculture in southern China using multi-temporal MODIS images. Remote Sensing of Environment, 95, 480-492. 